\title{
Towards Opto-structural Correlation to Investigate Luminescence Thermometry in an Organometallic Eu(II) Complex
}

\author{
Roberto M. Diaz-Rodriguez,§ Diogo A. Gálico,§ Daniel Chartrand, Elizaveta A. Suturina, \\ and Muralee Murugesu* \\ R. M. Diaz-Rodriguez, ${ }^{\S}$ Dr. D. A. Gálico, ${ }^{\S}$ Prof. Dr. M. Murugesu* \\ Department of Chemistry and Biomolecular Sciences \\ University of Ottawa \\ Ottawa, Ontario K1N 6N5 (Canada) \\ E-mail: M.Murugesu@uottawa.ca \\ $\S$ These authors contributed equally to this work. \\ Dr. D. Chartrand \\ Department of Chemistry, Université de Montréal \\ Montréal, Quebec H3T 1J4 (Canada) \\ Dr. E. A. Suturina \\ Department of Chemistry, University of Bath \\ Claverton Down, Bath BA2 7AY (UK)
}




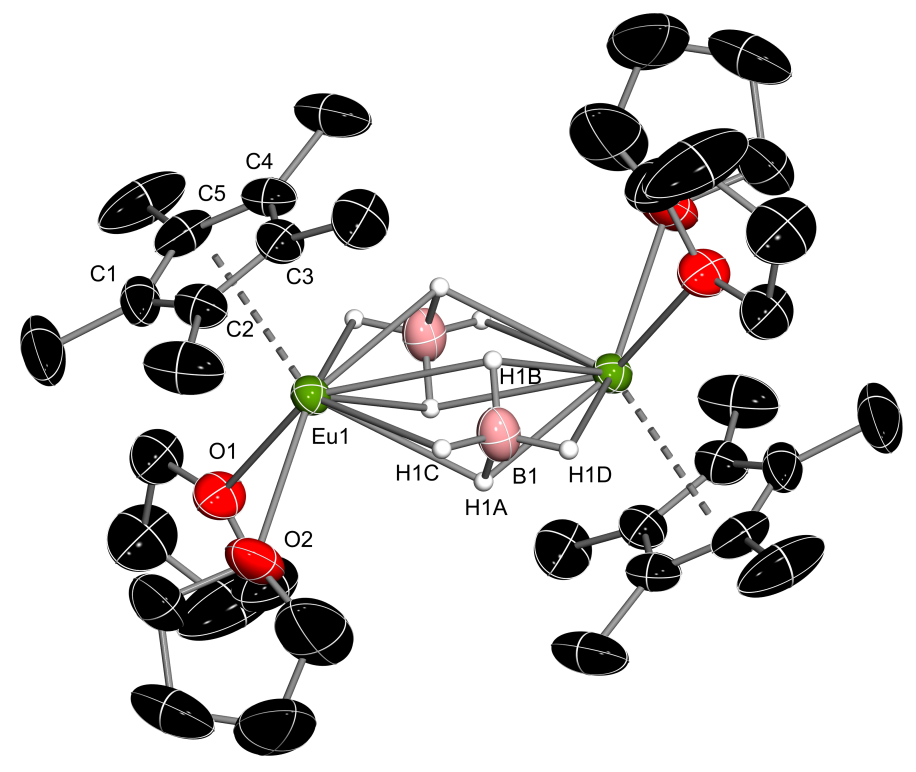

Figure S1. Thermal ellipsoid diagram (50\% probability) of 1. Hydrogen atoms bonded to carbon are omitted for clarity. Labels are given only for the crystallographically unique atoms which coordinate the $\mathrm{Eu}(\mathrm{II})$ centre; symmetry-related atoms are indicated elsewhere with a prime (e.g. B1').

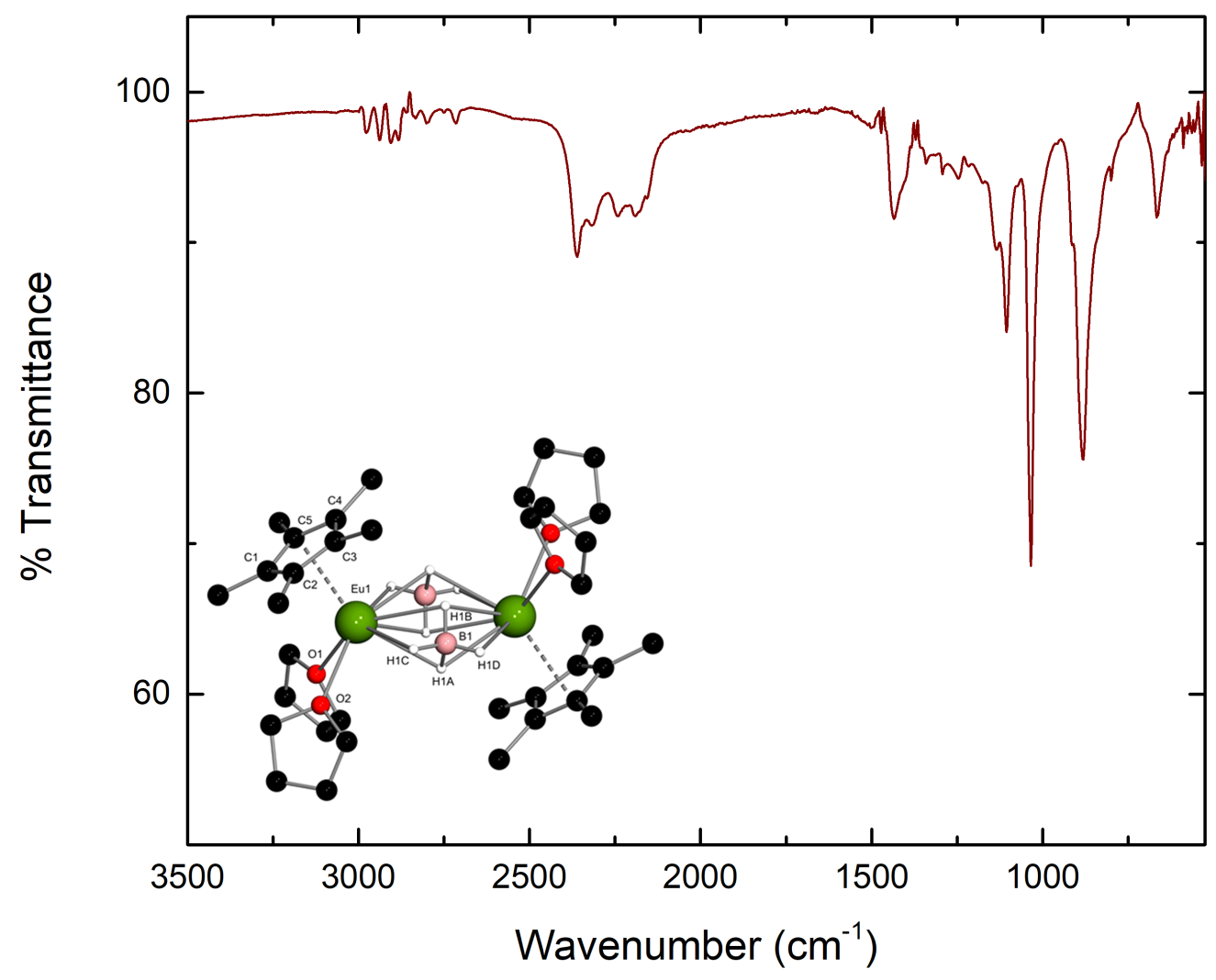

Figure S2. Infrared spectrum of complex 1. 


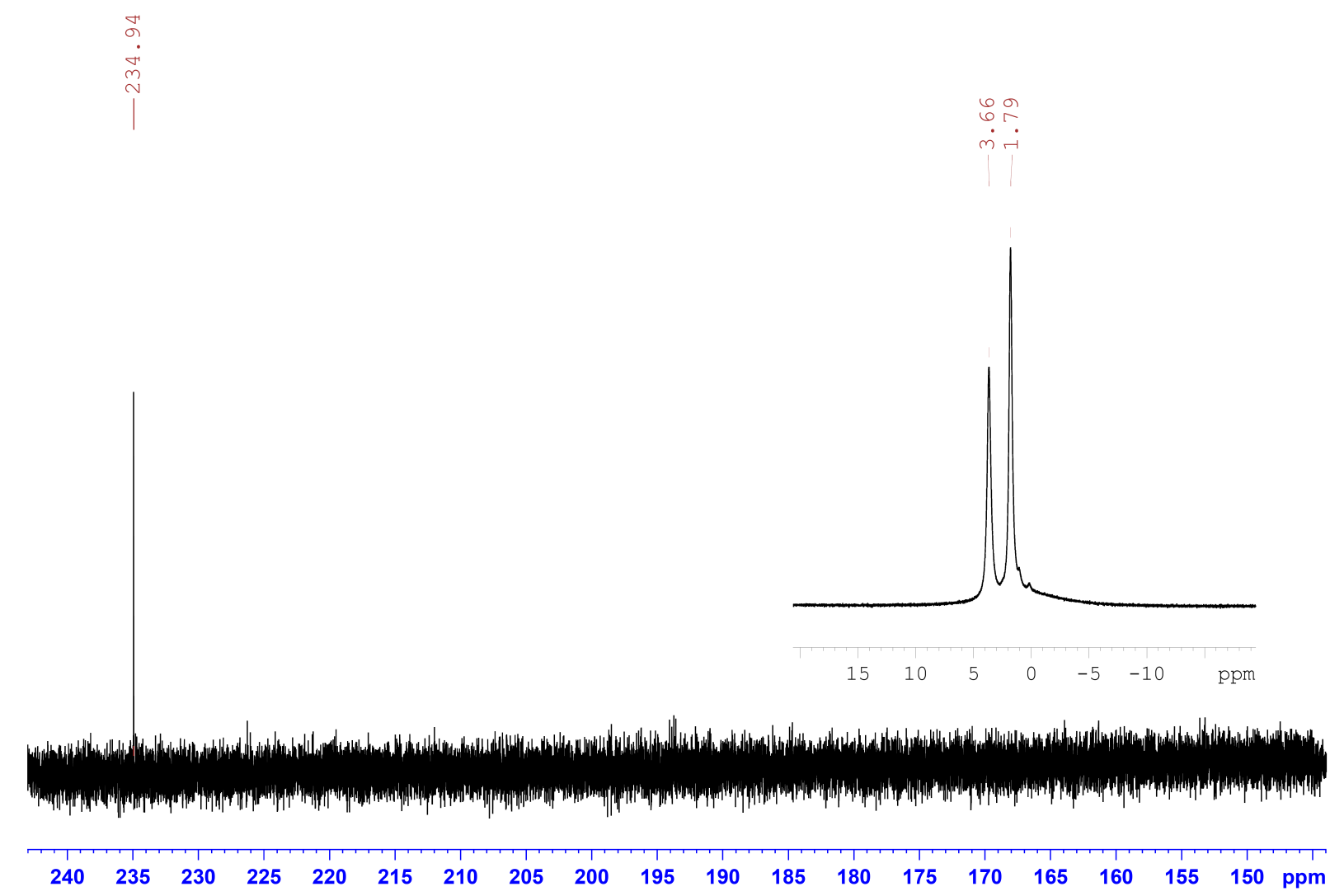

Figure S3. ${ }^{1} \mathrm{H}$ NMR spectrum of complex 1 in THF-d 8 . Note the extremely downfield-shifted resonance ascribable to the $\mathrm{Cp}^{*}$ methyl substituents, in addition to the resonances at 3.66 and $1.79 \mathrm{ppm}$ that are attributable to THF. Residual THF and coordinated THF are indistinguishable due to the broadness of the resonances.

\section{Magnetic Properties}

At $300 \mathrm{~K}$ and $1000 \mathrm{Oe}$, a $X^{\top}$ product of $15.68 \mathrm{~cm}^{3} \mathrm{~K} \mathrm{~mol}^{-1}$ is observed (Figure S4), which is in good agreement with the expected value of $15.76 \mathrm{~cm}^{3} \mathrm{~K} \mathrm{~mol}^{-1}$ for two non-interacting $4 f^{7},{ }^{8} S_{7 / 2}$ ions with $L=0$ and $g=2$. The $x^{\top}$ value remains essentially constant until approximately $20 \mathrm{~K}$, where it increases slowly to $16.93 \mathrm{~cm}^{3} \mathrm{~K} \mathrm{~mol}^{-1}$ at $6 \mathrm{~K}$ before increasing sharply to a maximum of $20.32 \mathrm{~cm}^{3} \mathrm{~K} \mathrm{~mol}^{-1}$ at $1.8 \mathrm{~K}$. This increase in $x^{\top}$ below $20 \mathrm{~K}$ can be attributed to weak ferromagnetic interactions between spin carriers occurring at low temperatures. This data can be fitted using the Hamiltonian $\mathcal{H}=-2 J S_{1} S_{2}$, which yields a small positive Eu-Eu coupling constant of $J=+0.04 \mathrm{~cm}^{-1}$. At $1.9 \mathrm{~K}$, the field-dependent magnetization reaches a value of $13.91 \mu_{\mathrm{B}}$ at a field of $7 \mathrm{~T}$ (Figure S5), which is in good agreement with the theoretical value of $14 \mu_{\mathrm{B}}$ for a system with ground state $S_{T}=7$. As expected for an isotropic system, complex 1 is devoid of any slow magnetic relaxation dynamics (i.e., no AC signal at zero field or under an applied DC field of $1000 \mathrm{Oe})$. 


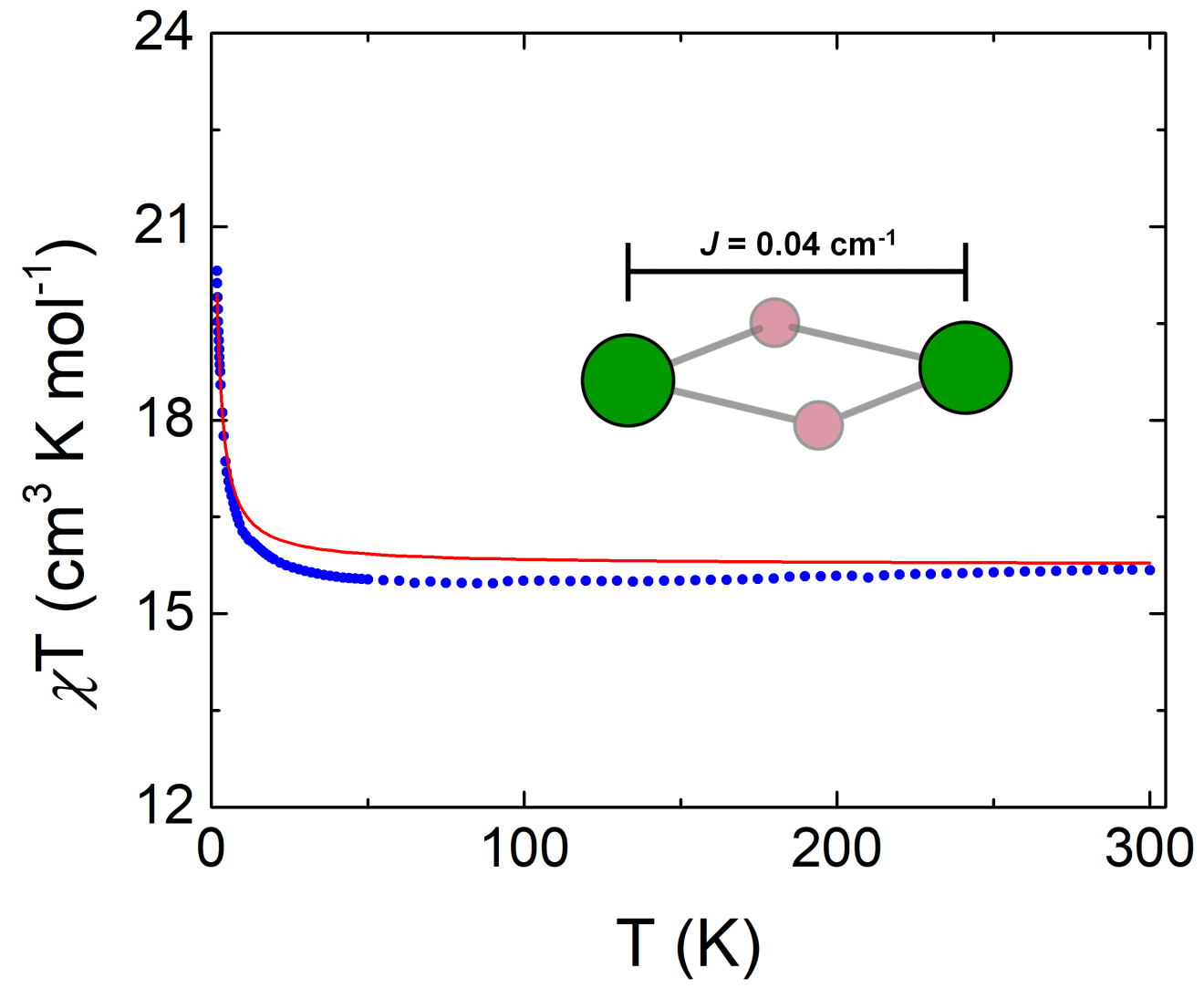

Figure S4. Temperature dependence of the $X^{\top}$ product at 1000 Oe (blue points) for complex $\mathbf{1}$, with $X$ being the molar magnetic susceptibility per molecule defined as $M / H$. The solid red line represents the fit; the calculated $J$ value is $+0.04 \mathrm{~cm}^{-1}$.
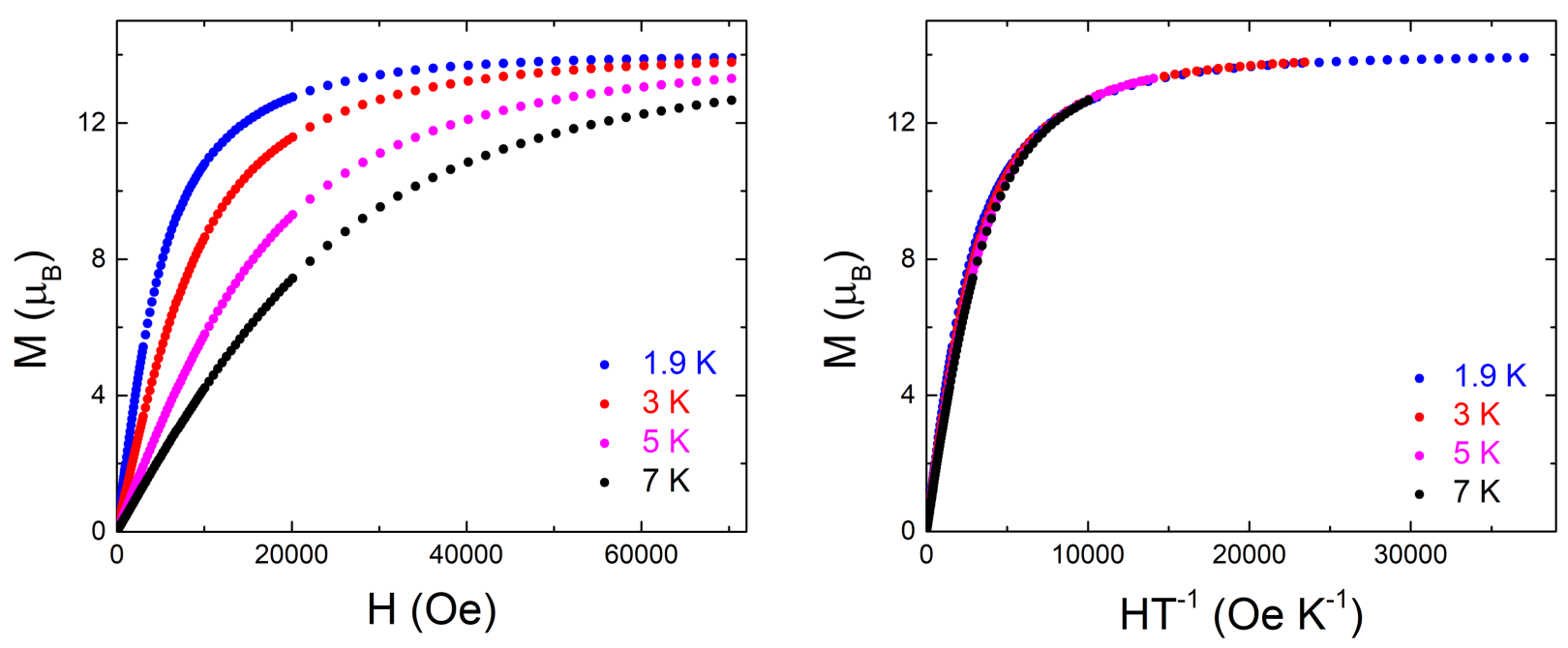

Figure S5. Field dependence of the magnetization (left) and reduced magnetization (right) for 1 at the indicated temperatures. 


\section{Electronic Structure Calculations}

Calculations have been carried out using the ORCA 4.1 program package on the crystal structure of 1 at $203.15 \mathrm{~K}$. Energies and corresponding spin densities have been computed with the B3LYP functional and def2-TZVP basis set on Eull and def2-SVP for the rest of the molecule. The exchange interaction has been computed using the broken-symmetry approach. The brokensymmetry solution is an open-shell singlet state, which corresponds to a spin flip on one of the sites. The exchange coupling constant $(J)$ is then computed as

$$
J=-\frac{E_{H S}-E_{B S}}{\left\langle S^{2}\right\rangle_{H S}-\left\langle S^{2}\right\rangle_{B S}}
$$

Where $E_{H S}$ and $\left\langle S^{2}\right\rangle_{H S}$ are the energy and the expectation value of the squared spin operator of the maximum multiplicity state; $E_{B S}$ is the energy of the open-shell singlet; and $\left\langle S^{2}\right\rangle_{B S}$ its nonzero expectation value. This approach assumes the $\mathrm{H}=-2 \mathrm{JS}_{1} \mathrm{~S}_{2}$ Hamiltonian. Zero-field splitting (ZFS) and the $g$-tensor, as well as the energies of the $f$ - $f$ transitions, were calculated with OpenMolcas v19 with all-electron relativistic basis sets ANO-RCC-VTZP on lanthanides and ANO-RCC-VDZ for the rest of the molecule. One of the $\mathrm{Eu}^{\mathrm{ll}}$ ions was substituted by a diamagnetic $\mathrm{Yb}^{\prime \prime}$ ion. The active space consists of seven 4 -orbitals with 7 electrons. 1 octet, 48 sextet and 392 quartet states were calculated and mixed via spin-orbit coupling with the RASSI module.

The exchange coupling was found to be ferromagnetic, $\boldsymbol{J}=\mathbf{+ 0 . 0 6} \mathbf{~ c m}^{-1}$, that agrees well with the experimentally extracted parameter of $0.04 \mathrm{~cm}^{-1}$.

$\begin{array}{ll}\mathrm{S}(\text { High-Spin) } & =7.0 \\ <\mathrm{S}^{* *} 2>\text { (High-Spin) } & =56.0169 \\ <\mathrm{S}^{* *} 2>\text { (BrokenSym) } & =7.0168 \\ \mathrm{E}(\text { High-Spin) } & =-3182.058714 \mathrm{E}_{\mathrm{h}} \\ \mathrm{E}(\text { BrokenSym) } & =-3182.058701 \mathrm{E}_{\mathrm{h}}\end{array}$

The spin density plot shows an almost spherical spin distribution about each Eu" site, characteristic for the half-filled $f$-shell. There is almost no spin delocalisation onto the bridging $\mathrm{BH}_{4}$ fragments.

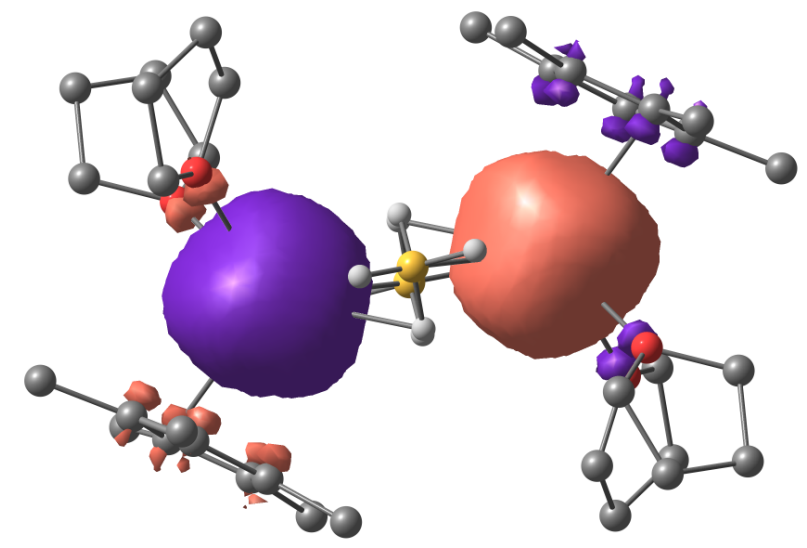

Figure S6. Spin density plot (iso-value 0.001 ) of the broken-symmetry solution for 1. 
The ZFS of the Eull octet ground state is within $1 \mathrm{~cm}^{-1}$. The exact energies (in $\mathrm{cm}^{-1}$ ) are:

0.000

0.000

0.159

0.159

0.386

0.386

0.743

0.743

and this can be described by the relatively small ZFS parameters $D=0.0598 \mathrm{~cm}^{-1}$ and $E=0.0066 \mathrm{~cm}^{-1}$. The $g$-tensor is isotropic, and the $g$-factor is $1.9972(\cong 2.00)$.

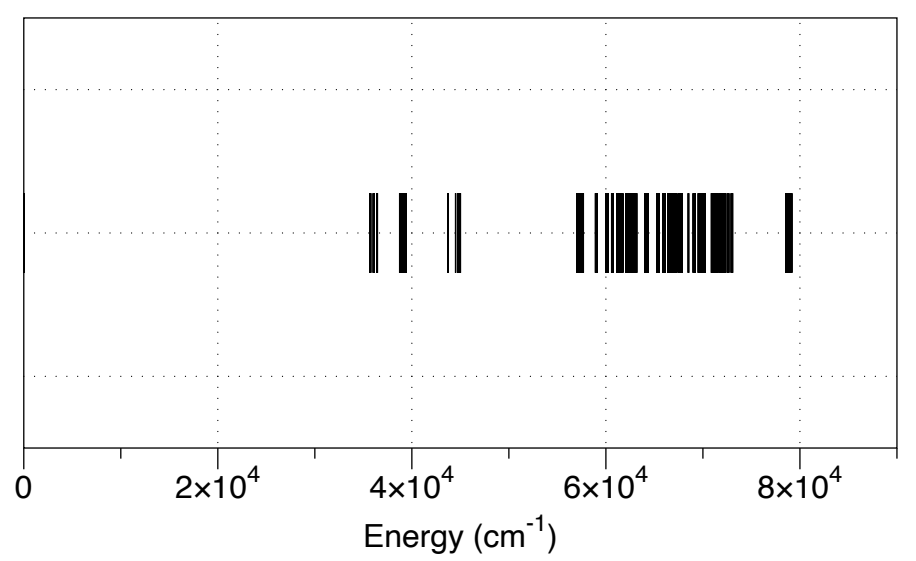

Figure S7. Computed energies of the excited states arising from $f$ - $f$ transitions in 1.

$A b$ initio ligand field calculations were performed on monomeric fragments of the $90 \mathrm{~K}$ and $270 \mathrm{~K}$ crystal structures (vide infra) with SOC-CASSCF(7,7)/NEVPT2 using def2-TZVP basis set for Eu and def2-SVP for the rest of the molecule. The $f$-orbital splitting and ligand field parameters are extracted based on the energy and wavefunctions of 1 octet and 48 sextet states.

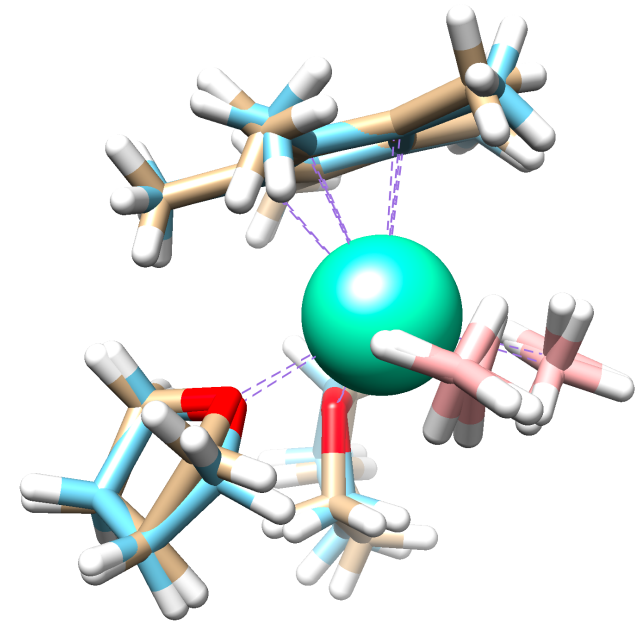

Figure S8. Comparison of the $90 \mathrm{~K}$ and $270 \mathrm{~K}$ crystal structures of a mononuclear fragment of 1. 


\section{$270 \mathrm{~K}$ ligand field parameters:}

$\mathrm{F} 2=0.398686471$ a.u. $=10.849 \mathrm{eV}=87501.6 \mathrm{~cm}^{-1}$

$\mathrm{F} 4=0.262175443$ a.u. $=7.134 \mathrm{eV}=57540.9 \mathrm{~cm}^{-1}$

$\mathrm{F} 6=0.186061113$ a.u. $=5.063 \mathrm{eV}=40835.7 \mathrm{~cm}^{-1}$

The ligand field one-electron eigenfunctions:

$\begin{array}{ccc}\text { Orbital } & \begin{array}{c}\text { Energy } \\ (\mathrm{eV})\end{array} & \begin{array}{c}\text { Energy }\left(\mathrm{cm}^{-}\right. \\ 1)\end{array} \\ 1 & 0.000 & 0.0 \\ 2 & 0.004 & 35.5 \\ 3 & 0.013 & 102.3 \\ 4 & 0.019 & 157.3 \\ 5 & 0.029 & 233.3 \\ 6 & 0.038 & 310.2 \\ 7 & 0.048 & 389.3\end{array}$

$f-3$
0.270410
0.428549
0.035528
-0.589526
0.567544
0.007398
0.268812

$f-2$
0.790765
-0.214254
0.521000
0.135966
-0.043216
0.134945
-0.137042

$f-1$
0.008013
0.240480
-0.228208
0.154814
0.348976
0.390450
-0.769301

f0
0.351294
-0.571289
-0.705449
-0.212454
0.068088
0.034509
0.039991

$f+1$

$-0.176909$

$-0.102834$

0.104280

$-0.245708$

$-0.222140$

0.884770

0.233918

$\begin{array}{cc}\mathrm{f}+2 & \mathrm{f}+3 \\ & \\ 0.346090 & -0.164386 \\ 0.531293 & -0.305602 \\ -0.395614 & 0.100865 \\ 0.483538 & 0.520276 \\ -0.215457 & 0.673675 \\ 0.160460 & 0.139743 \\ 0.368050 & 0.354059\end{array}$

\section{$90 \mathrm{~K}$ ligand field parameters:}

$\mathrm{F} 2=0.398940993$ a.u. $=10.856 \mathrm{eV}=87557.4 \mathrm{~cm}^{-1}$

$\mathrm{F} 4=0.262619569$ a.u. $=7.146 \mathrm{eV}=57638.3 \mathrm{~cm}^{-1}$

$\mathrm{F} 6=0.186198988$ a.u. $=5.067 \mathrm{eV}=40866.0 \mathrm{~cm}^{-1}$

The ligand field one electron eigenfunctions:

$\begin{array}{ccc}\text { Orbital } & \begin{array}{c}\text { Energy } \\ (\mathrm{eV})\end{array} & \begin{array}{c}\text { Energy }\left(\mathrm{cm}^{-}\right. \\ 1)\end{array} \\ 1 & 0.000 & 0.0 \\ 2 & 0.008 & 65.1 \\ 3 & 0.012 & 94.8 \\ 4 & 0.022 & 179.0 \\ 5 & 0.031 & 251.8 \\ 6 & 0.042 & 340.4 \\ 7 & 0.050 & 404.8\end{array}$

$f-3$
-0.413362
-0.331818
-0.078206
-0.527007
0.630161
-0.156983
0.115888

$f-2$
-0.719885
0.387737
-0.434326
0.270000
-0.016727
0.243054
-0.102629

f-1

0.003531

$-0.331091$

0.216702

0.049019

0.168905

0.598420

$-0.674069$

f0
-0.161426
0.637455
0.679037
-0.307912
0.077971
0.038706
-0.064145

$\mathrm{f}+1$

0.181931

0.066340

$-0.136765$

$-0.287688$

$-0.020887$

0.741924

0.556905 $\mathrm{f}+2$

$-0.443433$

$-0.431596$

0.520968

0.356941

$-0.213430$

0.068005

0.410002 $\mathrm{f}+3$

0.234725

0.181416

0.084156

0.584791

0.722510

0.040009

The ligand field parameters are very similar for both geometries (the same within the accuracy of the $a b$ initio ligand field fitting).

$\lambda(\mathrm{nm})$

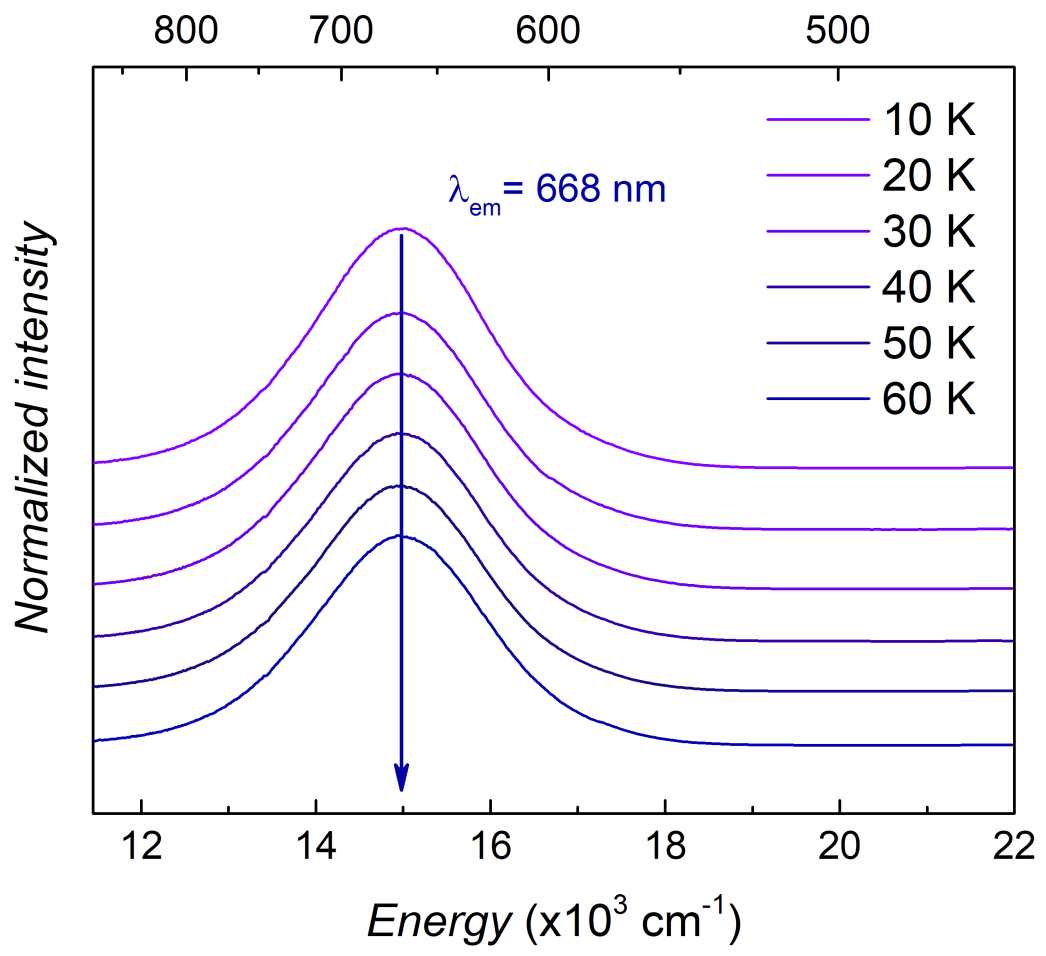

Figure S9. Solid-state emission spectra of crystalline $1\left(\lambda_{\mathrm{ex}}=330 \mathrm{~nm}\right)$ obtained in the $10-60 \mathrm{~K}$ range. Note that the emission peak energy remains constant over this temperature range. 


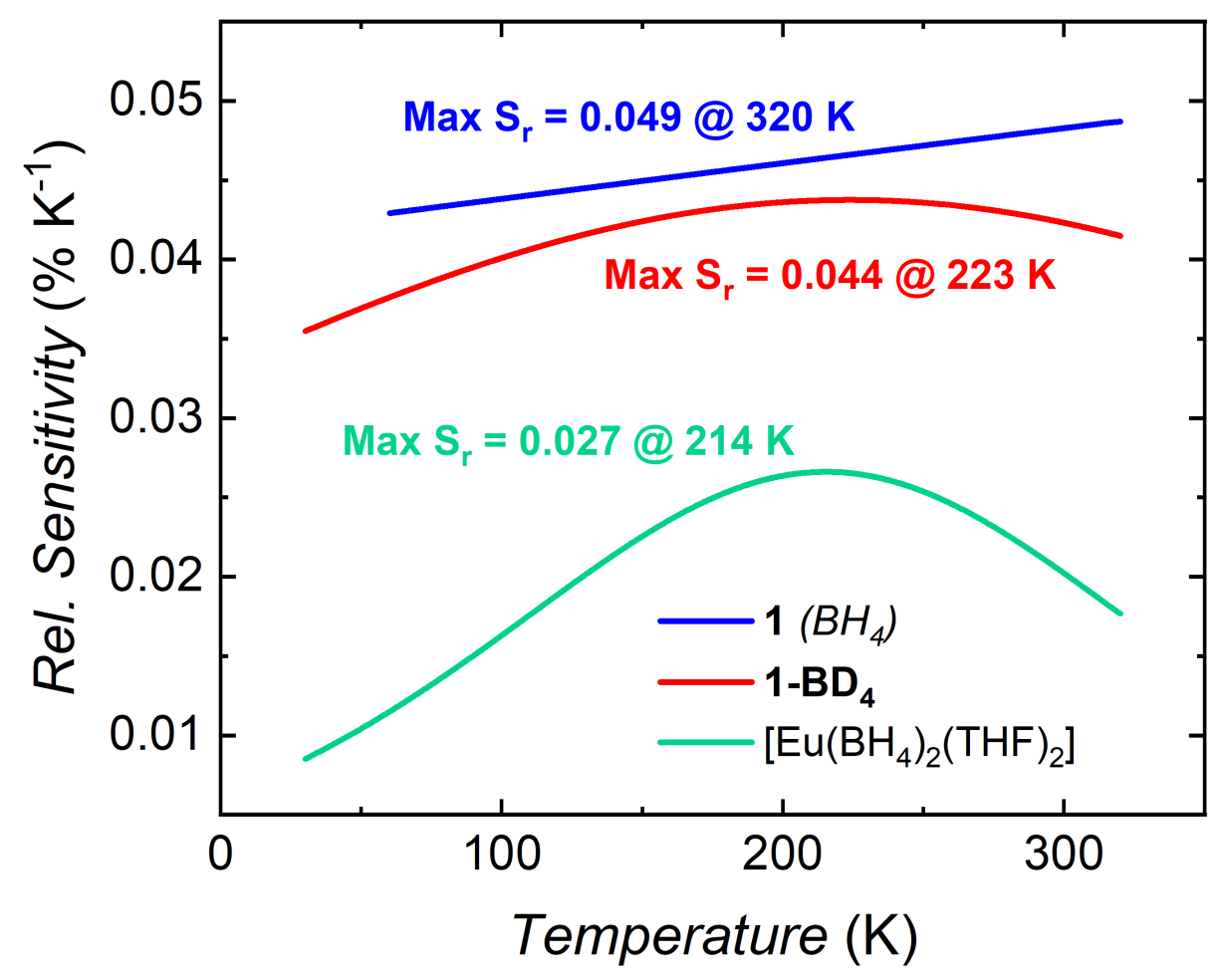

Figure S10. Relative sensitivities for 1, 1- $\mathrm{BD}_{4}$, and $\left.\left[\mathrm{Eu}(\mathrm{BH})_{2}\right)_{2}(\mathrm{THF})_{2}\right]$. Relative sensitivities were calculated with the equation: $S_{r}(\%)=[(\partial$ Peak position / $\partial T) /$ Peak position $] \times 100$.

To further evaluate the thermometric performance, the temperature uncertainty $\Delta T$, also known as the temperature resolution, was estimated. The $\Delta T$ parameter is extremely dependent on the instrumental setup, and correlates the instrumental error with the thermometer's sensitivities via the following equation:

$$
\Delta T=\frac{1}{S} * \sigma
$$

Where the sensitivity $S$ may be either absolute $\left(S_{a}\right)$ or relative $\left(S_{r}\right)$, and $\sigma$ is the absolute or relative instrumental error, depending on the chosen sensitivity. Most of the methodologies presented in the literature for calculating $\Delta T$ do so for intensity-based thermometric methods. For intensitybased methods, $\sigma$ is related to the detector's signal-to-noise ratio and is wavelength independent (except at the limits of the detector's wavelength range). Conversely, $\sigma$ for band-shift thermometry is extremely dependent on the wavelength range. Thus, $\sigma$ is associated with the wavelength accuracy and wavelength repeatability of the whole spectrofluorometer system (i.e., the monochromator/spectrograph size, gratings, and detector). Herein, we propose an estimation of $\Delta T$ for a band-shift thermometric setup, considering the wavelength dependence of different spectroscopic systems. For this, we select 3 hypothetical but typical instrumental peak resolution values:

System 1: $0.5 \mathrm{~nm}$ (commonly observed for portable optical detectors).

System 2: $0.1 \mathrm{~nm}$ (commonly observed for typical laboratory spectrometers).

System 3: $0.025 \mathrm{~nm}$ (commonly observed for high-resolution spectrometers). 
As the energy values are inversely proportional to the wavelength (Energy $=10^{7} / \lambda$ ), $\sigma$ possesses different values over different spectral regions (Figure S11a). Consequently, $\sigma$ values are higher in the blue region and smaller in the red region. For example, given a wavelength resolution of $0.025 \mathrm{~nm}$ (as for a high-resolution spectrometer), the value of $\sigma$ is $0.61 \mathrm{~cm}^{-1}$ at $650 \mathrm{~nm}$ (red region) and $1.24 \mathrm{~cm}^{-1}$ at $450 \mathrm{~nm}$ (blue region). Therefore, for different band-shift thermometers possessing the same temperature sensitivity, the one with the emission occurring at longer wavelengths/lower energies will result in smaller $\Delta T$ (i.e., higher temperature resolution). Figures S11b-d show the temperature uncertainty for the three complexes studied in this work.
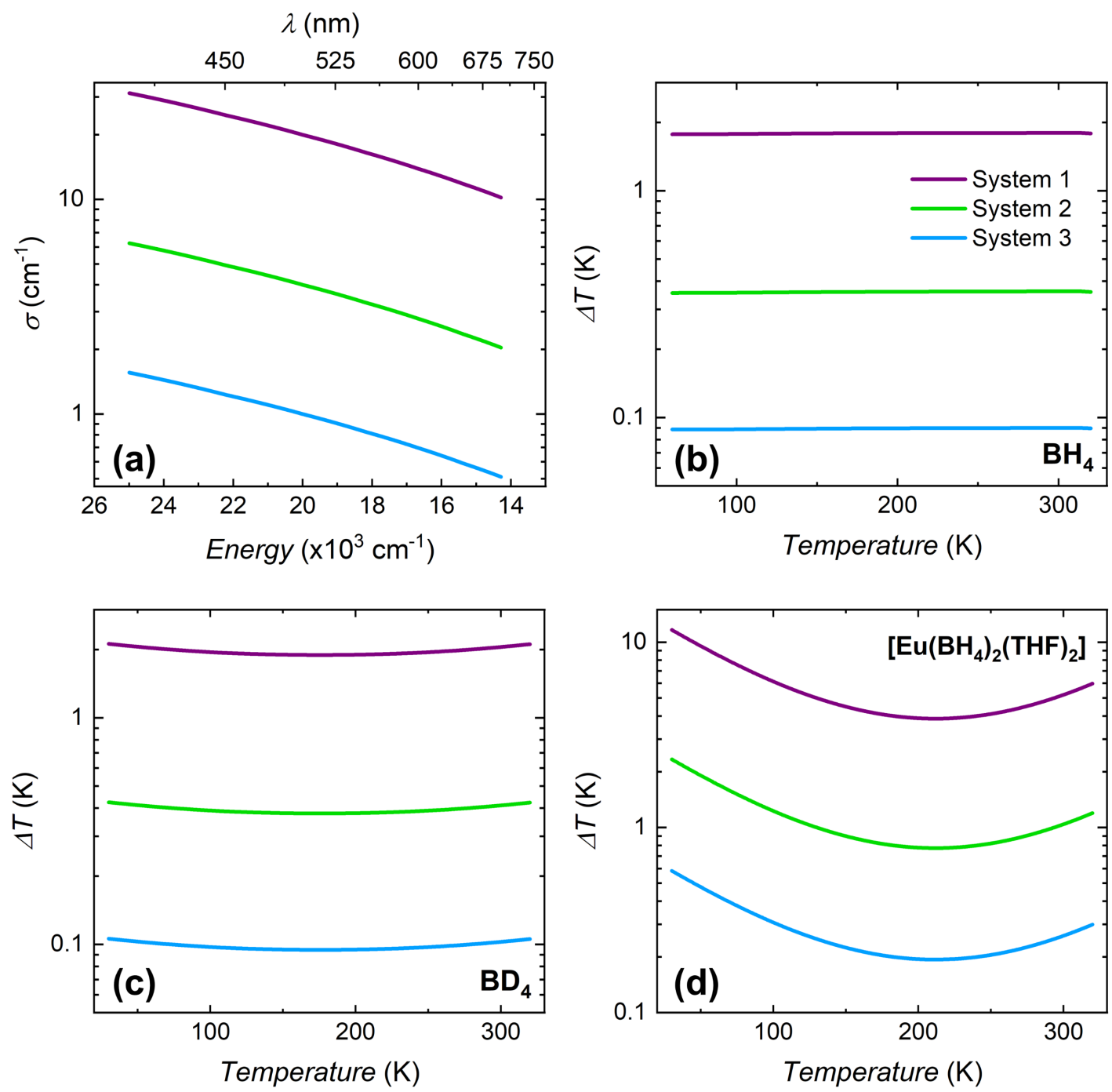

Figure S11. (a) Wavelength dependence of the instrumental error $\sigma$ for three different spectroscopic systems. Temperature uncertainty $\Delta T$ values for (b) $\mathbf{1}$, (c) $\mathbf{1 - B D _ { 4 }}$ and (d) $\left[\mathrm{Eu}^{\prime \prime}\left(\mathrm{BH}_{4}\right)_{2}(\mathrm{THF})_{2}\right]$ (lower is better). 

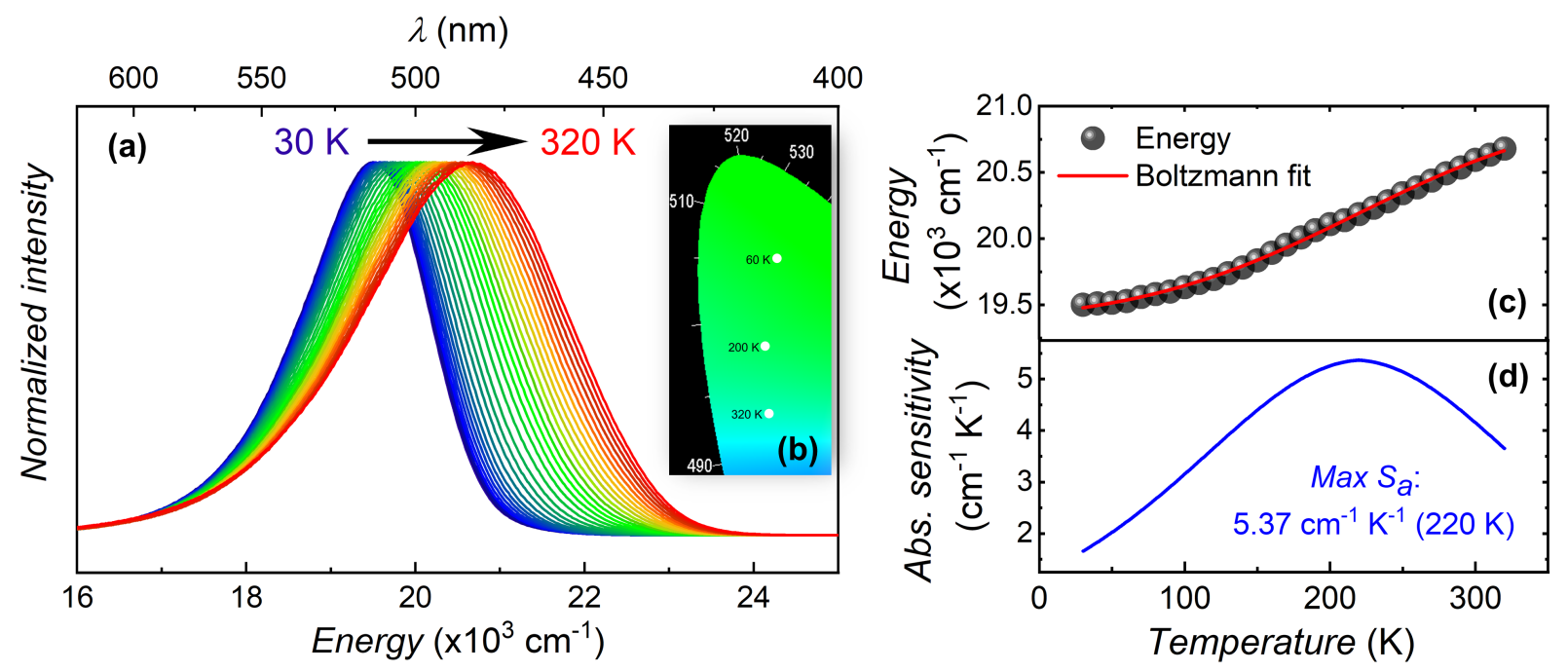

Figure S12. Temperature-dependent emission of [Eu" $\left.\left(\mathrm{BH}_{4}\right)_{2}(\mathrm{THF})_{2}\right]$. (a) Temperature-dependent emission spectra $\left(\lambda_{\mathrm{ex}}=330 \mathrm{~nm}\right)$ for 1 obtained in the solid state over the $30-320 \mathrm{~K}$ range with steps of $10 \mathrm{~K}$. (b) Relevant section of the CIE diagram showing the luminescence colors of $\left[\mathrm{Eu}^{\prime \prime}\left(\mathrm{BH}_{4}\right)_{2}(\mathrm{THF})_{2}\right]$ at selected temperatures. (c) Temperature-dependence of the emission peak energy. The red line represents the Boltzmann function (eq. 1) used to fit the experimental data. Best-fitting parameters: $r^{2}=0.998, A_{1}=19336, A_{2}=21033$, and $x_{0}=219$. (d) Absolute sensitivity obtained as the first derivative of the fitted function. 
Table S1. Selected bond lengths/interatomic distances and angles around europium of 1.

\begin{tabular}{cc|cc}
\hline Bond or Interatomic distance & Length $(\AA)$ & Entry & Angle $\left(^{\circ}\right)$ \\
\hline Eu1-Cp*(cent) & $2.5185(3)$ & Cp*$^{*}$ (cent)-Eu1-B1 & $115.064(59)$ \\
Eu1-O1 & $2.6064(16)$ & B1-Eu1-O2 & $85.661(71)$ \\
Eu1-O2 & $2.6097(20)$ & O2-Eu1-O1 & $72.878(65)$ \\
Eu1-B1 & $2.8746(26)$ & O1-Eu1-Cp*(cent) & $115.866(46)$ \\
Eu1-B1' & $2.9389(36)$ & O2-Eu1-B1' & $136.792(73)$ \\
Eu1-Eu1' & $4.2616(5)$ & O1-Eu1-B1 & $128.736(68)$ \\
\hline
\end{tabular}

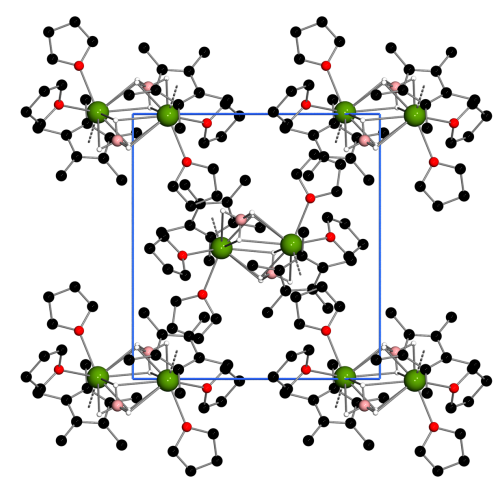

A

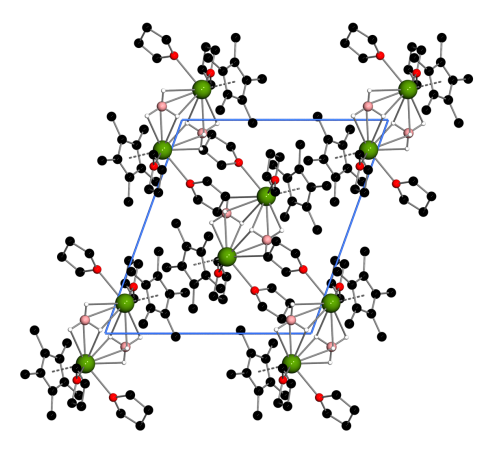

B

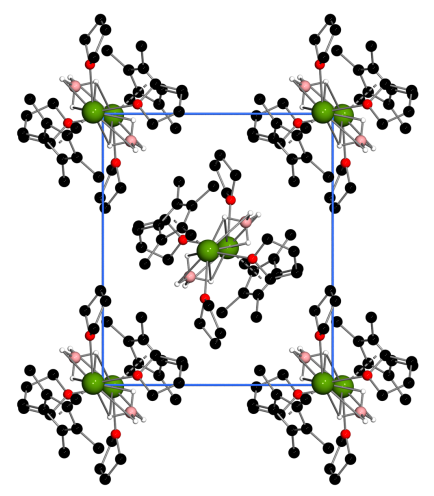

C

Figure S13. Crystallographic packing diagrams of 1 , shown along the a) a-axis, b) $b$-axis, and c) $c$-axis of the unit cell. Hydrogen atoms bonded to carbon are omitted for clarity. 
Table S2. Selected metrical parameters from crystal structures of 1 at various temperatures, in comparison to the emission peak energy.

\begin{tabular}{|c|c|c|c|c|c|c|c|c|c|c|c|}
\hline $\begin{array}{c}\text { Temperature } \\
\text { (K) }\end{array}$ & $\begin{array}{l}\text { Eu-Cp*(cent) } \\
\text { distance }(\AA)\end{array}$ & $\begin{array}{c}\text { Avg. Eu- } \\
\text { O(THF) } \\
\text { distance ( }(\AA)\end{array}$ & $\begin{array}{c}\text { Avg. Eu-B } \\
\text { distance }(\AA)\end{array}$ & $\begin{array}{c}\mathrm{B} 1-\mathrm{B} 1^{\prime} \\
\text { distance }(\AA)\end{array}$ & $\begin{array}{l}\text { B1-Eu-B1' } \\
\text { angle }\left({ }^{\circ}\right)\end{array}$ & $\begin{array}{c}\text { Intramolecular } \\
\text { Eu-Eu' distance } \\
(\AA)\end{array}$ & $\begin{array}{l}\text { Avg. of all Eu- } \\
\text { ligand bonds } \\
(\AA)\end{array}$ & $\begin{array}{l}\text { Unit cell } \\
\text { volume } \\
\qquad\left(\AA^{3}\right)\end{array}$ & $\begin{array}{l}\text { Crystal } \\
\text { density } \\
\left(\mathrm{g} / \mathrm{cm}^{3}\right)\end{array}$ & $\begin{array}{c}\text { Closest } \\
\text { intermolecular Eu- } \\
\text { Eu distance }(\AA)\end{array}$ & $\begin{array}{c}\text { Emission } \\
\text { peak energy } \\
\left(\mathrm{cm}^{-1}\right)\end{array}$ \\
\hline 90 & $2.5259(5)$ & $2.5917(60)$ & $2.8885(132)$ & $3.9258(158)$ & $85.608(351)$ & $4.2387(7)$ & $2.6687(66)$ & $2015.6(2)$ & 1.470 & $9.3132(8)$ & 15124 \\
\hline 175 & $2.5224(3)$ & $2.6071(23)$ & $2.9019(41)$ & $3.9547(51)$ & $85.899(108)$ & $4.2483(4)$ & $2.6771(22)$ & $2058.2(1)$ & 1.440 & $9.4142(4)$ & $15721^{[b]}$ \\
\hline 200 & $2.5226(4)$ & $2.6011(53)$ & $2.9015(105)$ & $3.9399(142)$ & $85.521(278)$ & $4.2606(7)$ & $2.6750(54)$ & 2068.3(2) & 1.433 & $9.4553(6)$ & 15900 \\
\hline 203 & $2.5185(3)$ & $2.6081(18)$ & $2.9068(31)$ & $3.9547(41)$ & $85.720(81)$ & $4.2616(5)$ & $2.6778(17)$ & $2071.6(2)$ & 1.431 & $9.4600(5)$ & $15925^{[b]}$ \\
\hline 270 & $2.5222(4)$ & $2.5976(61)$ & $2.9233(134)$ & $3.9594(154)$ & $85.248(283)$ & $4.3022(7)$ & $2.6810(66)$ & $2108.7(2)$ & 1.406 & $9.5211(6)$ & 16412 \\
\hline$\Delta(\text { parameter })^{[a]}$ & - & - & +0.0349 & +0.0336 & -0.360 & +0.0635 & +0.0124 & +93.1 & -0.064 & +0.2079 & +1288 \\
\hline
\end{tabular}

[a] Change in the corresponding parameter over the selected temperature range, expressed in the indicated units. [b] Interpolated using the Boltzmann-type equation described in the main text.

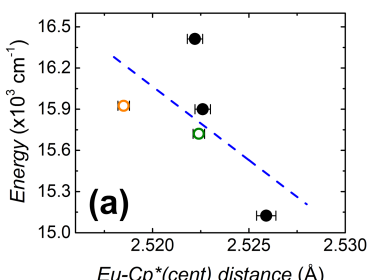

Eu-Cp $p^{*}($ ent) $\operatorname{distance}(\AA)$

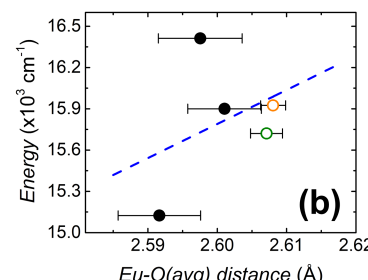

Eu-O(avg) distance ( $(\AA)$

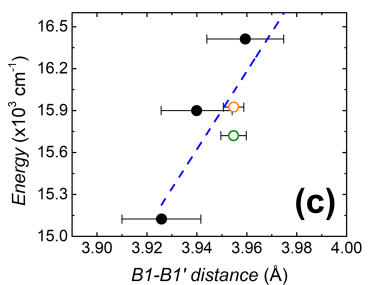

$B 1-B 1^{\prime}$ distance (A)

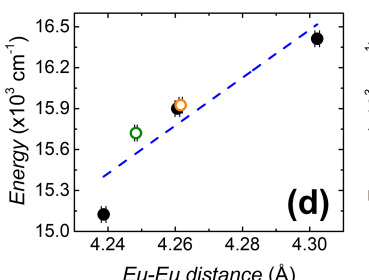

Eu-Eu distance (A)

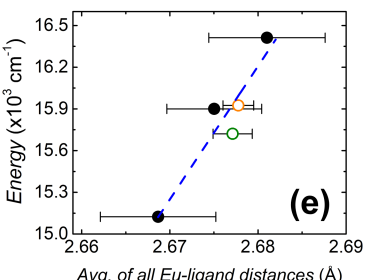

Avg of all Euligand distances (A)

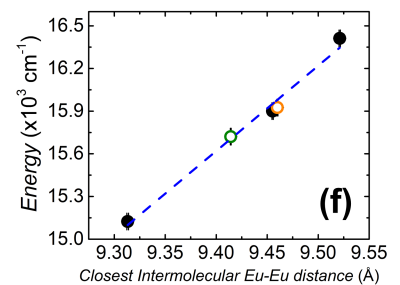

Figure S14. Plots of the emission peak energy of 1 as a function of the Eu-Cp*(cent) distance (a), the average Eu-O(THF) distance (b), the B1-B1' distance (c), the intramolecular Eu-Eu' distance (d), the average of all Eu-ligand distances (e), and the closest intermolecular Eu-Eu distance (f). The open green points represent data collected for a different crystal using the same diffractometer. The open orange points represent data collected on a different crystal using a different diffractometer. This demonstrates the consistency of the change in metrical parameters across the entire sample. Error bars are shown but overlap the points in some cases. The dashed blue lines are linear fits of the data to the equation $y=m x+b$. Best fitting parameters are as follows: (a) no correlation; (b) no correlation; (c) $m=27.9, b=-94.5, R^{2}=0.5989$; (d) $m=17.6, b=-59.0, R^{2}=0.7859$; (e) $m=95.8, b=-240, R^{2}=0.8628$; (f) $m=5.99, b=-40.7, R^{2}=0.9832$. 
Table S3. Shape analysis of 1, from the $203 \mathrm{~K}$ crystal structure, using SHAPE 2.1. Values in table are the continuous shape measures (dimensionless) for each idealized geometry.

\begin{tabular}{cccccc}
\hline Complex & $\begin{array}{c}\text { Pentagon } \\
\left(\mathrm{D}_{5 \mathrm{~h}}\right)\end{array}$ & $\begin{array}{c}\text { Vacant octahedron } \\
\left(\mathrm{C}_{4 \mathrm{v}}\right)\end{array}$ & $\begin{array}{c}\text { Trigonal bipyramid } \\
\left(\mathrm{D}_{3 \mathrm{~h}}\right)\end{array}$ & $\begin{array}{c}\text { Spherical } \\
\text { square } \\
\text { pyramid }\left(\mathbf{C}_{4 \mathrm{v}}\right)\end{array}$ & $\begin{array}{c}\text { Johnson trigonal } \\
\text { bipyramid J12 } \\
\left(\mathrm{D}_{3 \mathrm{~h}}\right)\end{array}$ \\
\hline $\mathbf{1}$ & 32.724 & 4.752 & 4.856 & $\mathbf{1 . 2 3 6}$ & 8.129 \\
\hline
\end{tabular}
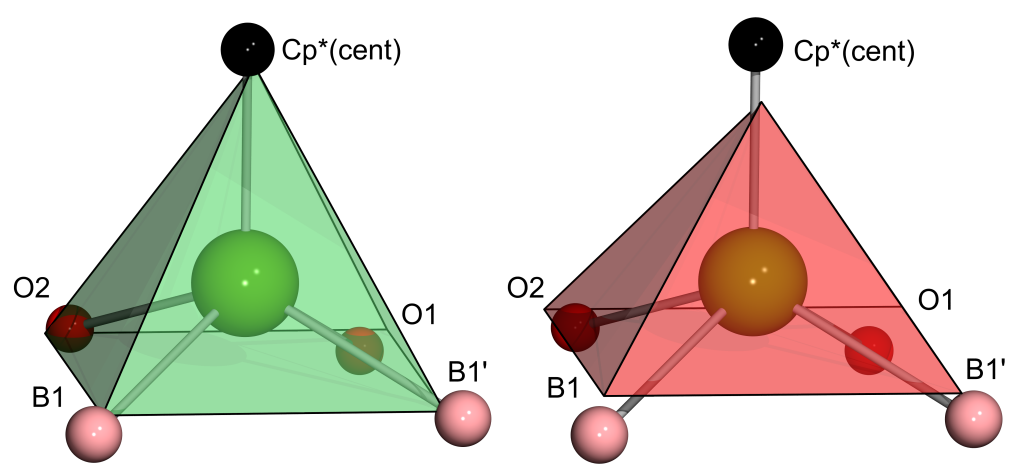

Figure S15. Left: comparison of the idealized square pyramidal geometry (green polyhedron) to the actual coordination sphere of 1 . Right: comparison of the next-best-fitting idealized geometry (vacant octahedron, red polyhedron), demonstrating the poor agreement of this model with the real structure. 


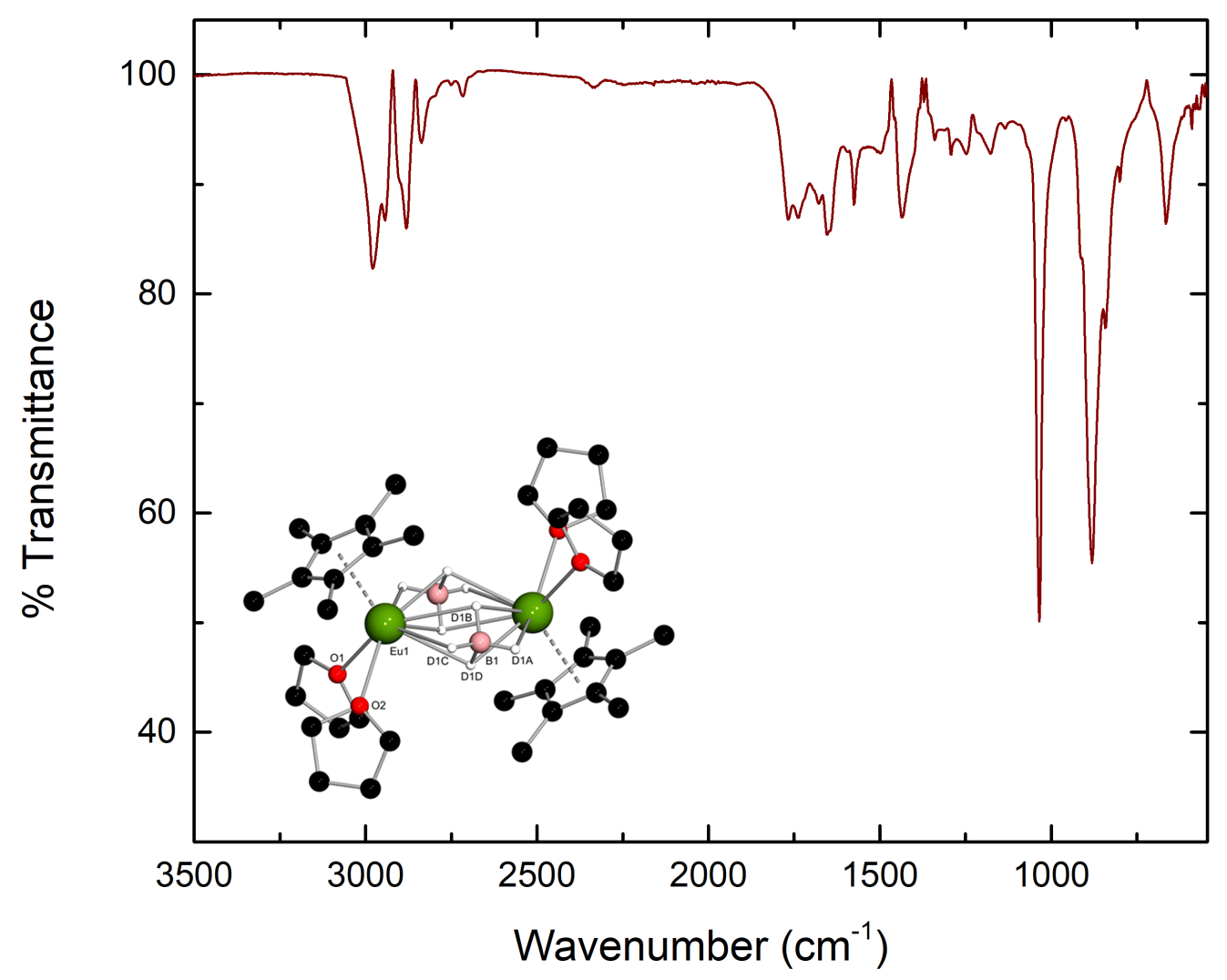

Figure S16. Infrared spectrum of complex $1-\mathbf{B D}_{4}$.
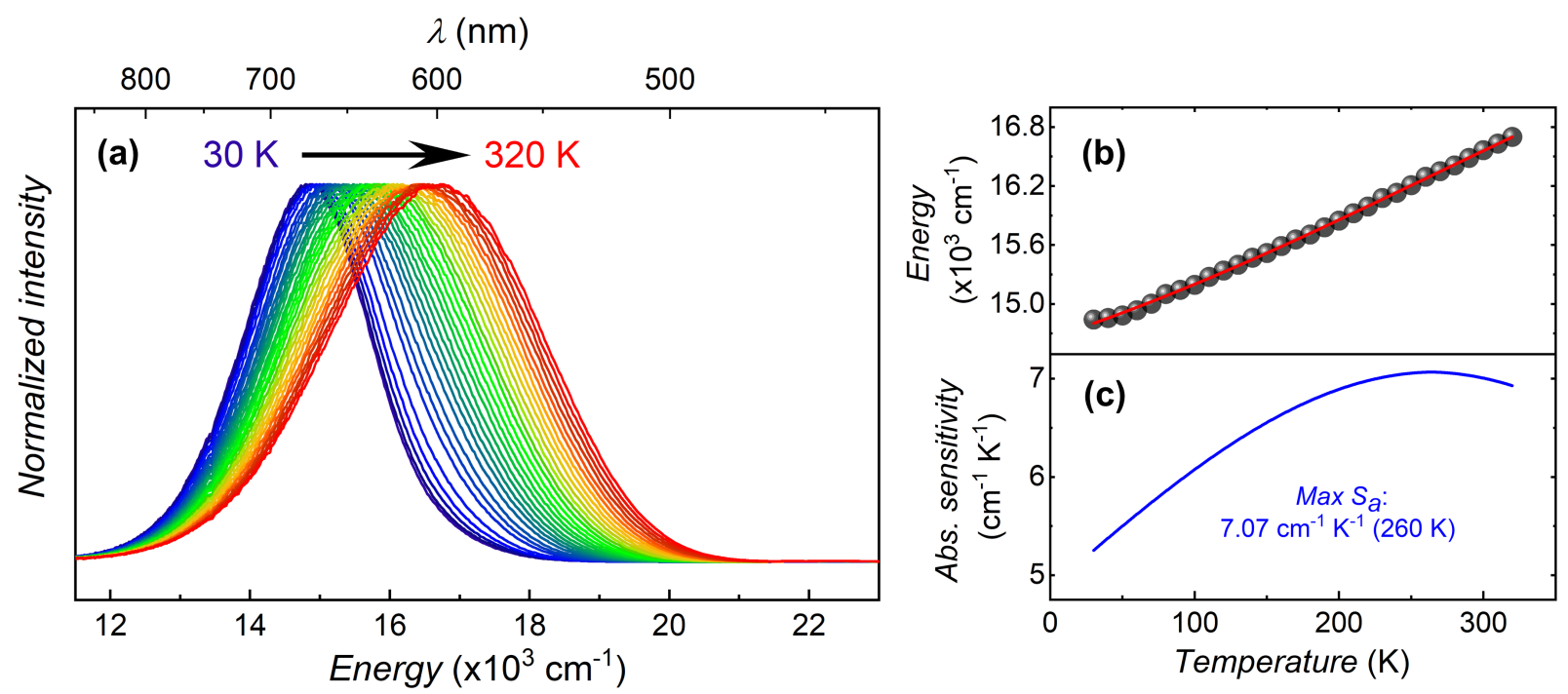

Figure S17. Temperature-dependent emission of 1-BD 4 . (a) Temperature-dependent emission spectra $\left(\lambda_{\mathrm{ex}}=330 \mathrm{~nm}\right)$ for $1-\mathrm{BD}_{4}$ obtained in the solid state over the $30-320 \mathrm{~K}$ range with steps of $10 \mathrm{~K}$. (b) Temperature-dependence of the emission peak energy. The red line represents the Boltzmann function (eq. 1) used to fit the experimental data. Best-fitting parameters: $r^{2}=0.999$, $A_{1}=13362, A_{2}=19214$, and $x_{0}=261$. (c) Absolute sensitivity obtained as the first derivative of the fitted function. 


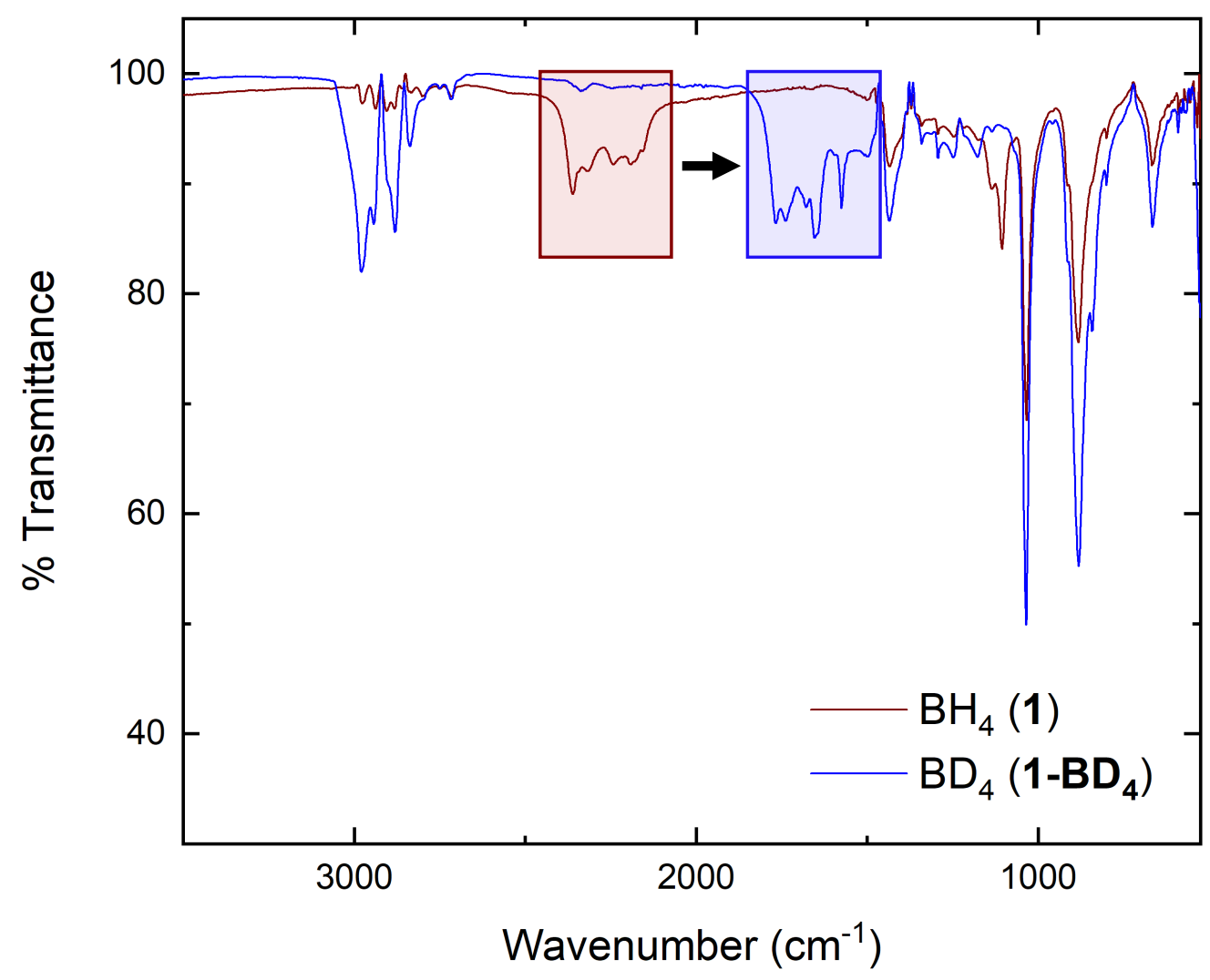

Figure S18. Infrared spectra of 1 and $1-\mathrm{BD}_{4}$ overlaid for comparison. The centre frequency of the $\mathrm{BX}_{4}$ vibration band shifts by $630 \mathrm{~cm}^{-1}$ upon substitution of $\mathrm{D}$ for $\mathrm{H}$, from approx. $2260 \mathrm{~cm}^{-1}$ to approx. $1630 \mathrm{~cm}^{-1}$. A very weak absorbance is observed at $2337 \mathrm{~cm}^{-1}$ in the spectrum of 1-BD4, which is most likely due to a small amount of ${ }^{1} \mathrm{H}$ incorporation from the $98 \%-\mathrm{D} \mathrm{NaBD} 4$ used in the synthesis.

Table S4. Comparison of metrical parameters between 1 and $1-B^{4}$ at $203 \mathrm{~K}$.

\begin{tabular}{ccc}
\hline Parameter & 1 & 1-BD $_{4}$ \\
\hline Eu-Cp* $($ cent) distance $(\AA)$ & $2.5185(3)$ & $2.5208(6)$ \\
Eu-O $(\mathrm{avg})$ distance $(\AA)$ & $2.6081(18)$ & $2.6207(30)$ \\
Eu-B $(\mathrm{avg})$ distance $(\AA)$ & $2.9068(31)$ & $2.9060(58)$ \\
B1-B1' distance $(\AA)$ & $3.9547(41)$ & $3.9638(76)$ \\
Eu-Eu distance $(\AA)$ & $4.2616(5)$ & $4.2508(12)$ \\
Avg of Eu-L distances $(\AA)$ & $2.6778(17)$ & $2.6825(31)$ \\
Unit Cell Volume $\left(\AA^{3}\right)$ & $2071.6(2)$ & $2086.9(1)$ \\
Crystal Density $\left(\mathrm{g} / \mathrm{cm}^{3}\right)$ & 1.431 & 1.433 \\
\hline
\end{tabular}




\section{Absorption Spectra Calculations}

TD-DFT absorption spectra were calculated for the same monomeric fragments derived from the $90 \mathrm{~K}$ and $270 \mathrm{~K}$ crystal structures (Supplementary Figure 8), with the B3LYP functional and def2TZVP basis set on Eu and def2-SVP on the rest of the molecule, considering the first 50 excited states.

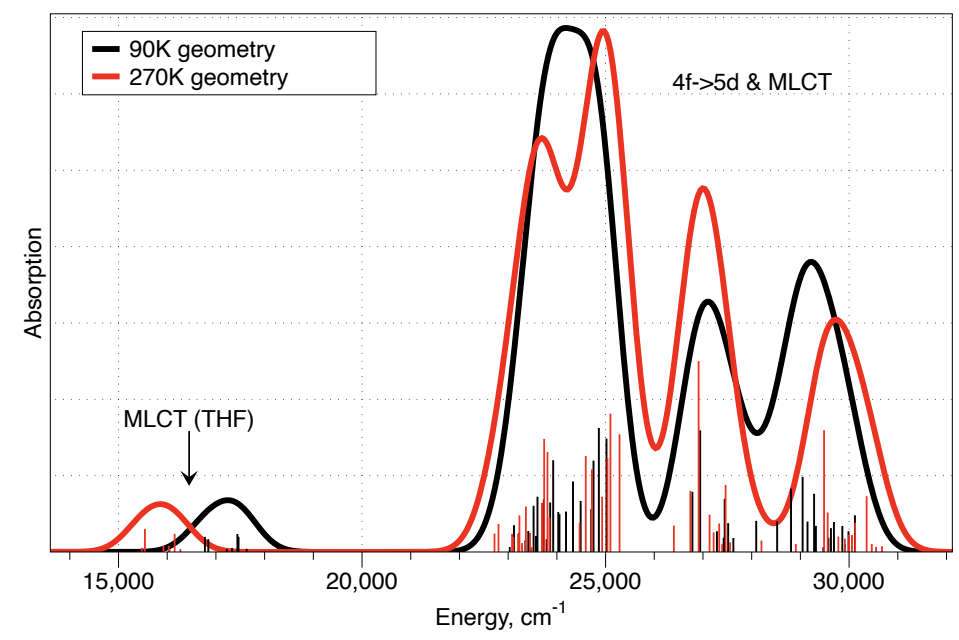

Figure S19. Computed TD-DFT absorption spectra of 1 calculated based on the crystal structures at $90 \mathrm{~K}$ (black) and $270 \mathrm{~K}$ (red). The bars represent vertical electronic transitions, and the envelope is obtained with $1000 \mathrm{~cm}^{-1}$ Gaussian broadening.

Small changes in the structure caused by the temperature increase seem to affect the low-lying metal to ligand (THF) charge transfer band $\left(15000-17000 \mathrm{~cm}^{-1}\right)$ the most, by shifting it $\sim 1500 \mathrm{~cm}^{-}$ ${ }^{1}$ to lower energy. Meanwhile, the $4 f-5 d$ bands (some of which are coupled with the MLCT band) exhibit much smaller shifts of $\sim 500 \mathrm{~cm}^{-1}$ to higher energies, accompanied by small changes in intensity.

The nature of transitions with large oscillator strength were identified using the difference in electronic densities between excited and ground states. 
Table S5. TD-DFT (B3LYP) calculated vertical excitations for the first 50 electronic transitions, with the corresponding oscillator strength and difference densities of 1 (truncated structure) measured at $90 \mathrm{~K}$ (isovalue 0.003 ). Transitions are sorted by their oscillator strength.

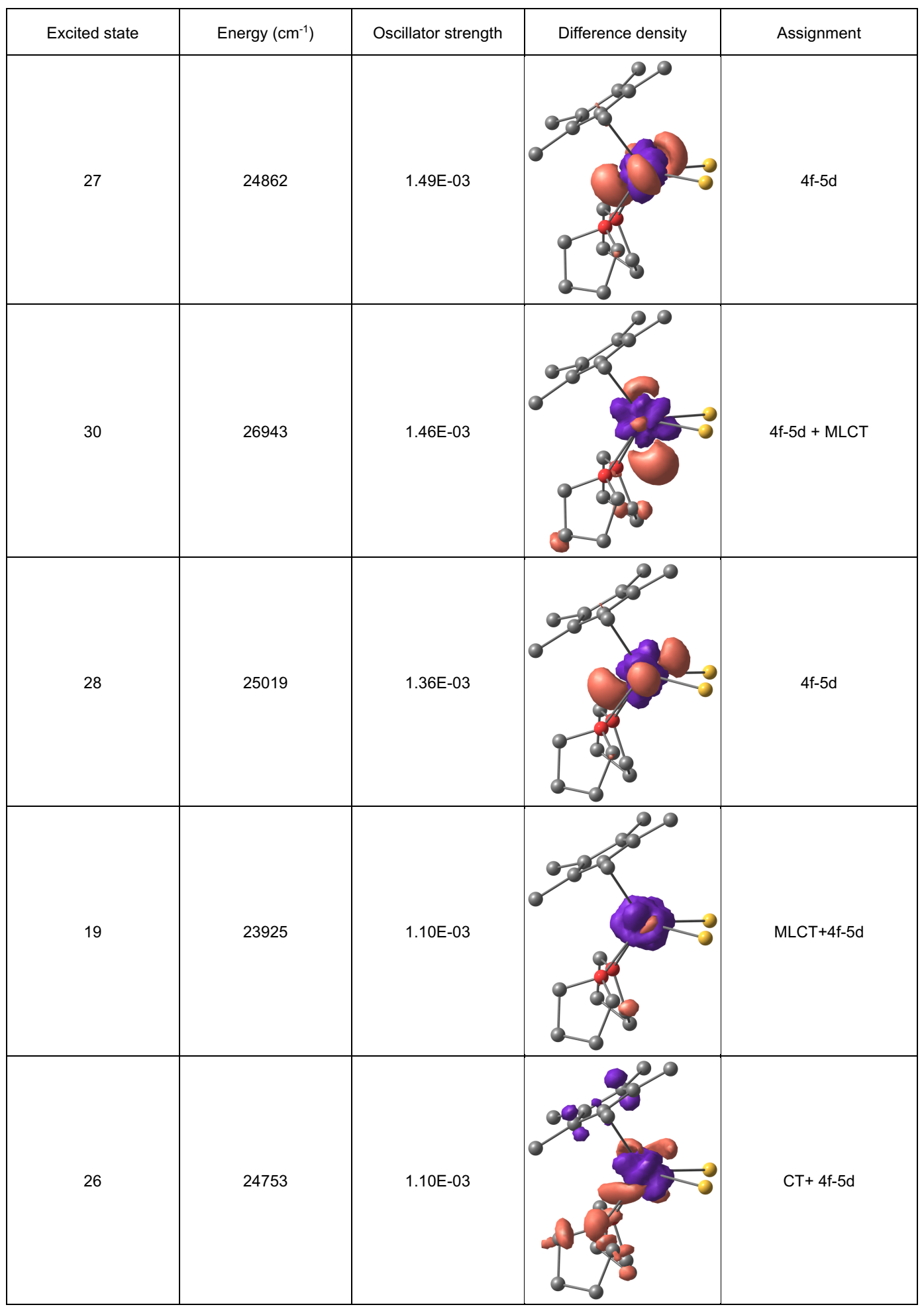




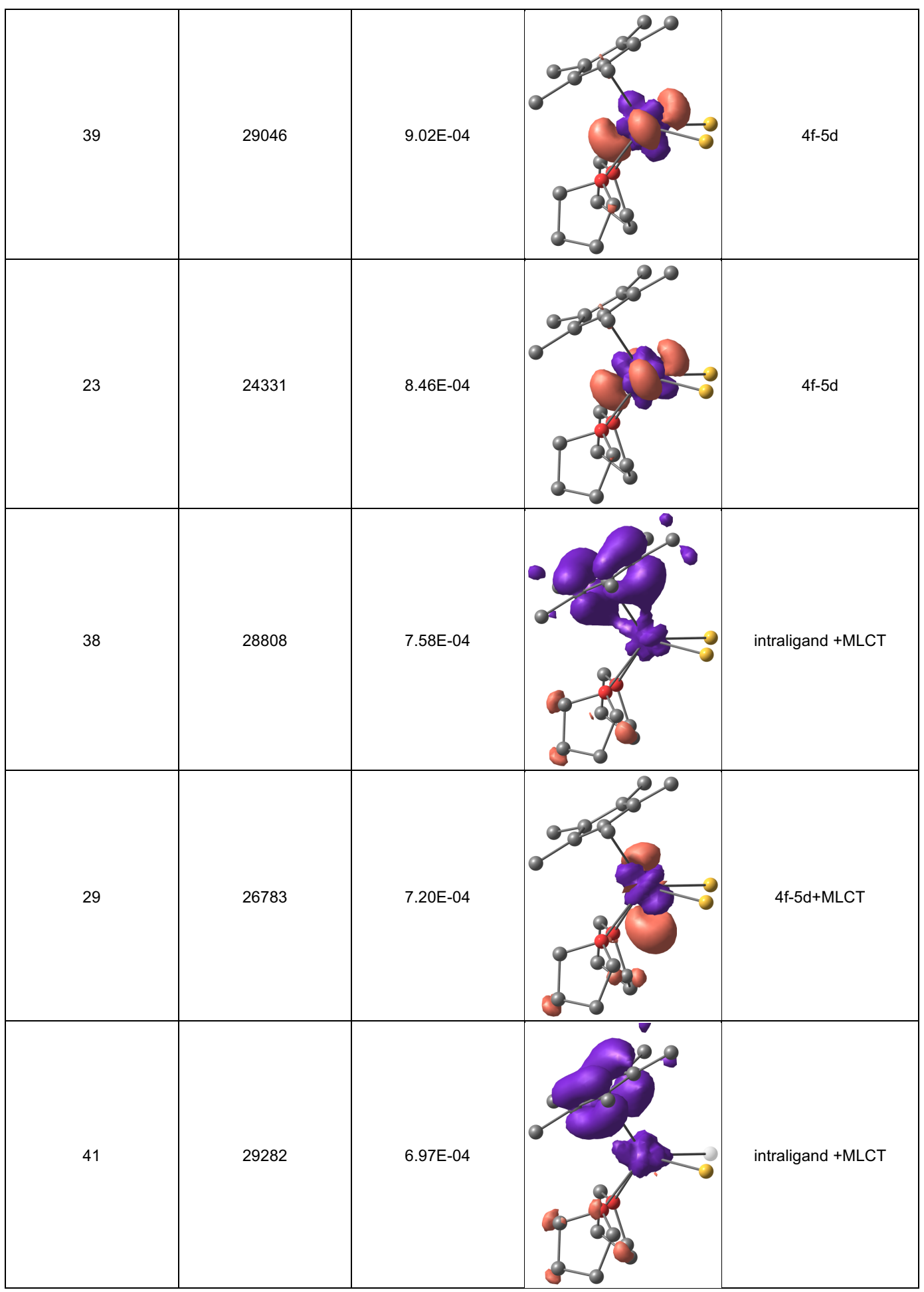




\begin{tabular}{|c|c|c|c|c|}
\hline 15 & 23602 & $6.62 \mathrm{E}-04$ & & $4 f-5 d$ \\
\hline 33 & 27446 & $6.36 \mathrm{E}-04$ & & $4 d-5 d+M L C T$ \\
\hline 16 & 23732 & $6.29 \mathrm{E}-04$ & & \\
\hline 24 & 24489 & $6.09 \mathrm{E}-04$ & & \\
\hline 18 & 23863 & $5.92 \mathrm{E}-04$ & & \\
\hline 13 & 23522 & 5.52E-04 & & \\
\hline 25 & 24706 & $5.11 \mathrm{E}-04$ & & \\
\hline 22 & 24188 & $4.82 \mathrm{E}-04$ & & \\
\hline 20 & 24029 & 4.76E-04 & & \\
\hline 21 & 24054 & $4.50 \mathrm{E}-04$ & & \\
\hline 50 & 30120 & 4.36E-04 & & \\
\hline 36 & 28093 & $3.70 \mathrm{E}-04$ & & \\
\hline 37 & 28523 & $3.64 \mathrm{E}-04$ & & \\
\hline 40 & 29147 & 3.62E-04 & & \\
\hline 46 & 29689 & 3.56E-04 & & \\
\hline 34 & 27517 & $3.41 \mathrm{E}-04$ & & \\
\hline 9 & 23120 & 3.17E-04 & & \\
\hline 42 & 29319 & $3.09 \mathrm{E}-04$ & & \\
\hline 47 & 29861 & $3.08 \mathrm{E}-04$ & & \\
\hline 45 & 29628 & $2.82 \mathrm{E}-04$ & & \\
\hline 12 & 23413 & $2.47 \mathrm{E}-04$ & & \\
\hline 31 & 27287 & $2.44 \mathrm{E}-04$ & & \\
\hline 49 & 29988 & $2.44 \mathrm{E}-04$ & & \\
\hline
\end{tabular}




\begin{tabular}{|c|c|c|c|c|}
\hline 10 & 23221 & $2.23 \mathrm{E}-04$ & & \\
\hline 5 & 17441 & 2.11E-04 & & \\
\hline 14 & 23572 & $1.88 \mathrm{E}-04$ & & \\
\hline 6 & 17464 & 1.77E-04 & & \\
\hline 1 & 16774 & 1.77E-04 & & \\
\hline 44 & 29576 & 1.66E-04 & & \\
\hline 32 & 27425 & $1.65 \mathrm{E}-04$ & & \\
\hline 35 & 27624 & 1.63E-04 & & \\
\hline 17 & 23789 & $1.49 \mathrm{E}-04$ & & \\
\hline 2 & 16844 & $1.48 \mathrm{E}-04$ & & \\
\hline 11 & 23354 & 1.37E-04 & & \\
\hline 48 & 29915 & $9.24 \mathrm{E}-05$ & & \\
\hline 8 & 23032 & $5.35 \mathrm{E}-05$ & & \\
\hline 43 & 29471 & $5.24 \mathrm{E}-05$ & & \\
\hline 4 & 17333 & 4.27E-05 & & \\
\hline 7 & 17630 & $3.19 \mathrm{E}-05$ & & \\
\hline 3 & 17225 & 2.71E-05 & & \\
\hline
\end{tabular}

Table S6. TD-DFT (B3LYP) calculated vertical excitations for the first 50 electronic transitions with the corresponding oscillator strength and difference densities of 1 (truncated structure) measured at $270 \mathrm{~K}$ (isovalue 0.003 ). Transitions are sorted by their oscillator strength.

\begin{tabular}{|l|l|l|l|c|}
\hline Excited state & Energy $\left(\mathrm{cm}^{-1}\right)$ & Oscillator strength & Assignment \\
\hline 31 & 26911 & & & \\
& & &
\end{tabular}




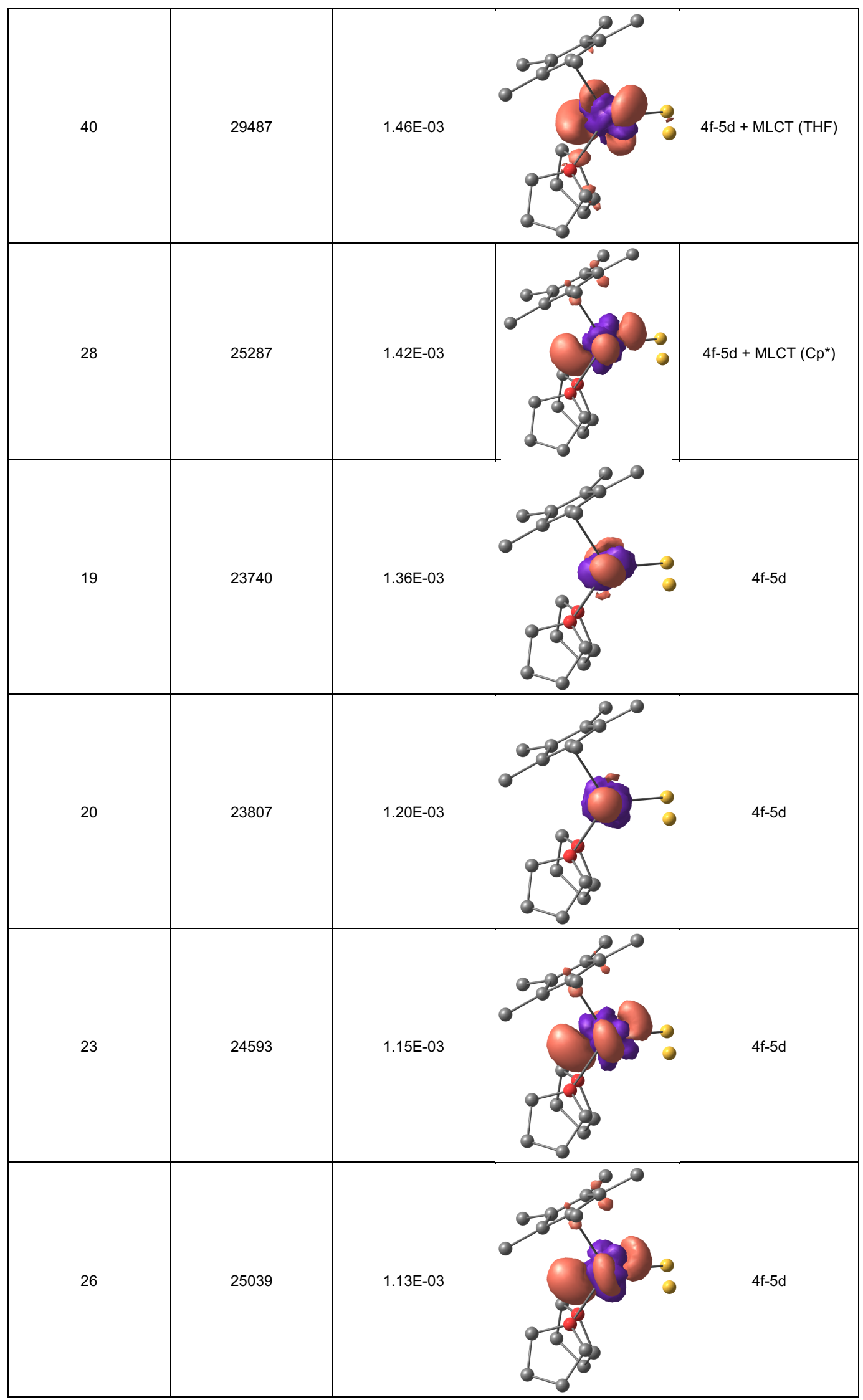




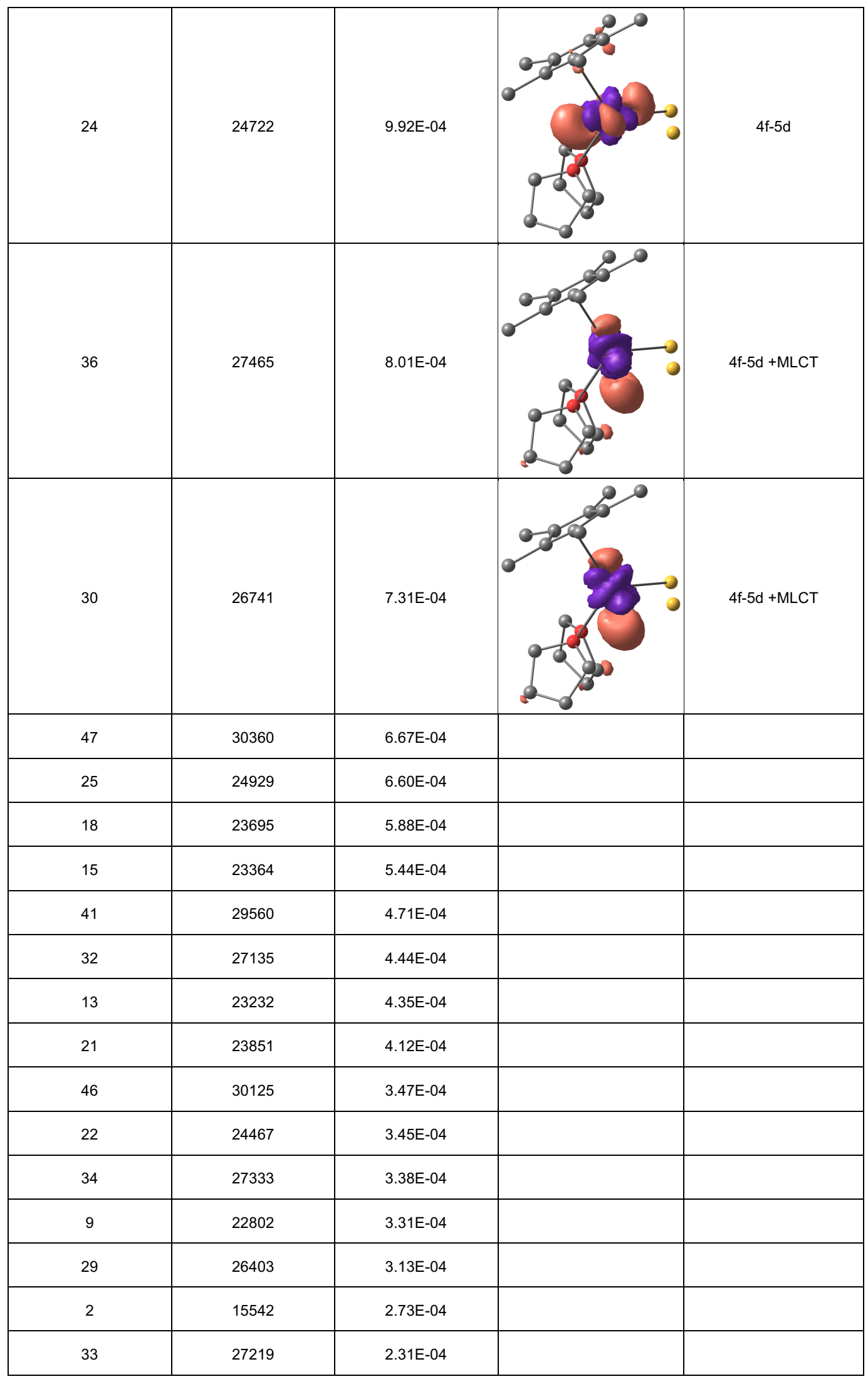




\begin{tabular}{|c|c|c|c|}
\hline 16 & 23448 & $2.25 \mathrm{E}-04$ & \\
\hline 8 & 22720 & 2.17E-04 & \\
\hline 6 & 16152 & $2.14 \mathrm{E}-04$ & \\
\hline 10 & 23080 & $2.13 \mathrm{E}-04$ & \\
\hline 12 & 23204 & $2.12 \mathrm{E}-04$ & \\
\hline 44 & 30000 & 2.05E-04 & \\
\hline 45 & 30059 & $1.98 \mathrm{E}-04$ & \\
\hline 42 & 29780 & $1.81 \mathrm{E}-04$ & \\
\hline 11 & 23109 & 1.77E-04 & \\
\hline 43 & 29913 & $1.56 \mathrm{E}-04$ & \\
\hline 38 & 28201 & $1.32 \mathrm{E}-04$ & \\
\hline 37 & 27557 & $1.10 \mathrm{E}-04$ & \\
\hline 14 & 23285 & $1.01 \mathrm{E}-04$ & \\
\hline 39 & 28907 & $9.12 \mathrm{E}-05$ & \\
\hline 48 & 30466 & $9.02 \mathrm{E}-05$ & \\
\hline 35 & 27394 & $8.79 \mathrm{E}-05$ & \\
\hline 4 & 16031 & $6.88 \mathrm{E}-05$ & \\
\hline 3 & 15923 & $6.66 \mathrm{E}-05$ & \\
\hline 50 & 30675 & $6.25 \mathrm{E}-05$ & \\
\hline 49 & 30554 & $5.56 \mathrm{E}-05$ & \\
\hline 17 & 23485 & $5.19 \mathrm{E}-05$ & \\
\hline 1 & 15479 & $4.50 \mathrm{E}-05$ & \\
\hline 5 & 16049 & $2.88 \mathrm{E}-05$ & \\
\hline 7 & 16271 & $2.86 \mathrm{E}-05$ & \\
\hline
\end{tabular}



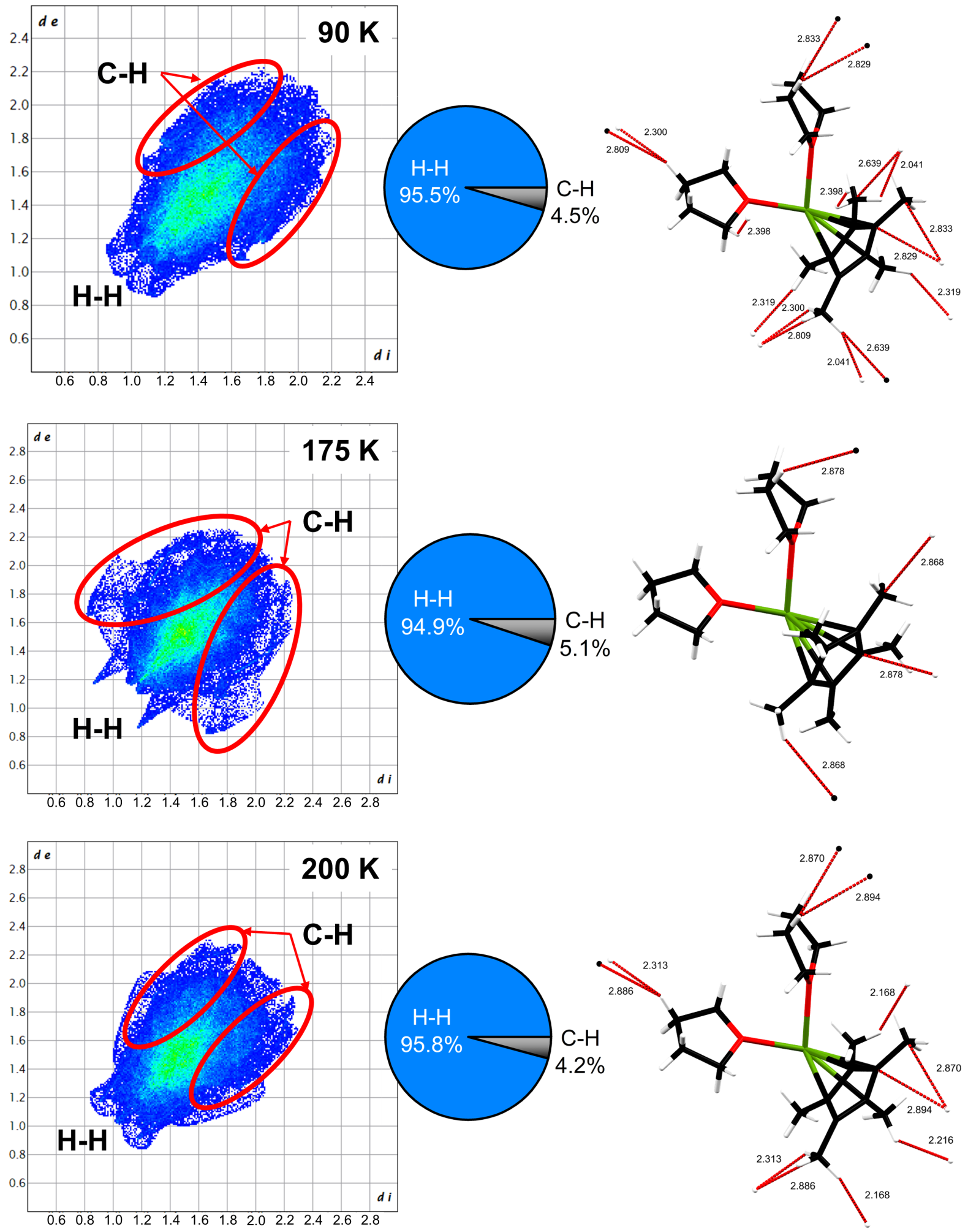

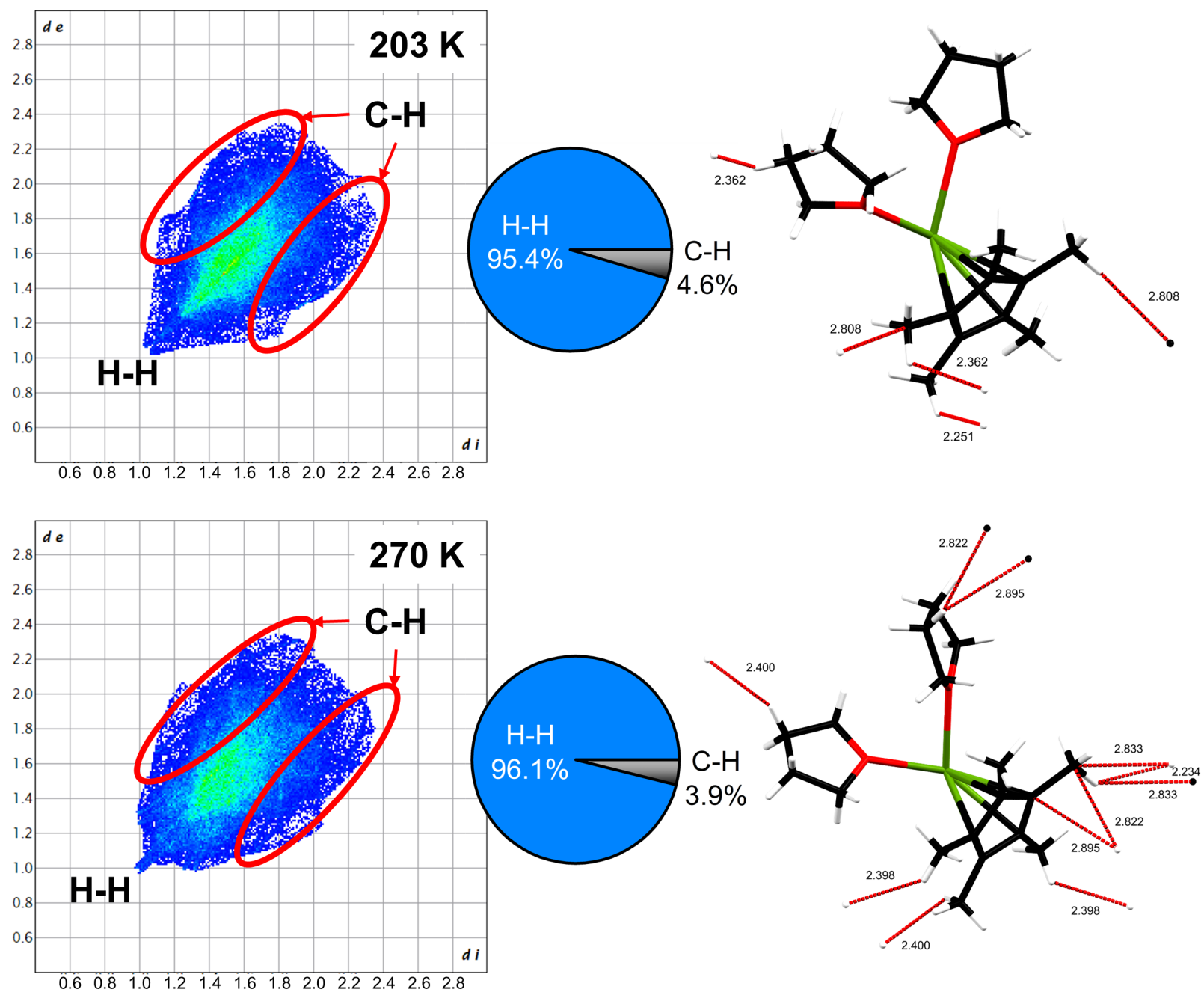

Figure S20. Visualization of the intermolecular interactions in 1 at various temperatures. Left to right: Hirshfeld fingerprint plot; sum of intermolecular contacts derived from the Hirshfeld surface analysis; and specific intermolecular contacts in the crystal structure, at each indicated temperature. Only the asymmetric unit is shown, and components of the molecule that do not participate in any intermolecular contacts are omitted for clarity. X-axis labels were added manually for clarity. 